\title{
Current and emerging strategies for the treatment and management of systemic lupus erythematosus based on molecular signatures of acute and chronic inflammation
}

\author{
This article was published in the following Dove Press journal: \\ Journal of Inflammation Research \\ I December 2010 \\ Number of times this article has been viewed
}

\author{
Undurti N Das \\ Jawaharlal Nehru Technological \\ University, Kakinada, Andhra Pradesh, \\ India; UND Life Sciences, Shaker \\ Heights, OH, USA
}

\begin{abstract}
Lupus is a chronic, systemic inflammatory condition in which eicosanoids, cytokines, nitric oxide (NO), a deranged immune system, and genetics play a significant role. Our studies revealed that an imbalance in the pro- and antioxidants and NO and an alteration in the metabolism of essential fatty acids exist in lupus. The current strategy of management includes administration of nonsteroidal anti-inflammatory drugs such as hydroxychloroquine and immunosuppressive drugs such as corticosteroids. Investigational drugs include the following: 1) belimumab, a fully human monoclonal antibody that specifically recognizes and inhibits the biological activity of B-lymphocyte stimulator, also known as B-cell-activation factor of the TNF family; 2) stem cell transplantation; 3) rituximab, a chimeric monoclonal antibody against CD20, which is primarily found on the surface of B-cells and can therefore destroy B-cells; and 4) IL-27, which has potent anti-inflammatory actions. Our studies showed that a regimen of corticosteroids and cyclophosphamide, and methods designed to enhance endothelial NO synthesis and augment antioxidant defenses, led to induction of long-lasting remission of the disease. These results suggest that methods designed to modulate molecular signatures of the disease process and suppress inflammation could be of significant benefit in lupus. Some of these strategies could be vagal nerve stimulation, glucose-insulin infusion, and administration of lipoxins, resolvins, protectins, and nitrolipids by themselves or their stable synthetic analogs that are known to suppress inflammation and help in the resolution and healing of the inflammation-induced damage. These strategies are likely to be useful not only in lupus but also in other conditions, such as rheumatoid arthritis, scleroderma, ischemia-reperfusion injury to the myocardium, ischemic heart disease, and sepsis.
\end{abstract}

Keywords: lupus, lipoxins, resolvins, polyunsaturated fatty acids, free radicals, rheumatology

\section{Introduction}

Systemic lupus erythematosus (SLE), a disease of unknown etiology that is more common in women than in men, is characterized by nondestructive arthritis/arthralgias, a cutaneous rash, vasculitis, involvement of the central nervous system (CNS), and renal and cardiopulmonary manifestations. Although genetic, environmental, and sex hormonal factors have been implicated in the pathogenesis of SLE (also called as 'lupus'), it is known that several cytokines, nitric oxide (NO), free radicals, a deranged immune system, deficient antioxidant defenses, and toll-like receptors have a significant role both in the initiation and perpetuation of the inflammatory process observed. The fundamental process in lupus appears to be rendering DNA and RNA antigenic, which leads to the production of anti-DNA and anti-RNA antibodies and the formation of 
immune complexes. These antibodies and immune complexes in turn trigger both a local and systemic inflammatory response that ultimately leads to target organ/tissue damage seen in lupus. The susceptibility for a given individual to develop lupus seems to have, at least partly, a genetic basis, though this is still not very clear. Once the inflammatory process is triggered, this leads to the production of a variety of proinflammatory cytokines such as interleukin (IL)-1, IL-6, tumor necrosis factor- $\alpha$ (TNF- $\alpha$ ), interferons (IFNs), macrophage migration inhibitory factor (MIF), HMGB-1 (high-mobility group B1), and possibly a reduction in the elaboration of anti-inflammatory cytokines such as IL-10, IL-4, and transforming growth factor- $\beta$ (TGF- $\beta$ ). This imbalance between the pro- and anti-inflammatory cytokines coupled with increased secretion of free radicals such as superoxide anion $\left(\mathrm{O}_{2}^{-}\right)$, hydrogen peroxide $\left(\mathrm{H}_{2} \mathrm{O}_{2}\right)$, singlet oxygen, inducible nitric oxide (iNO), and other reactive oxygen species (ROS) by activated monocytes, macrophages, polymorphonuclear leukocytes (PMNL), T-cells, Kupffer cells, glial cells in the brain, and other organ-specific reticuloendothelial cells would ultimately cause target tissue/organ damage seen in lupus (see Figure 1 for the formation of free radicals, NO, and reactive nitrogen intermediates). No lupus patients have the same manifestations, and the clinical presentation of the same patient at different time periods could be variable. For example, initially, a particular patient may present with cutaneous manifestations and over a period of time might

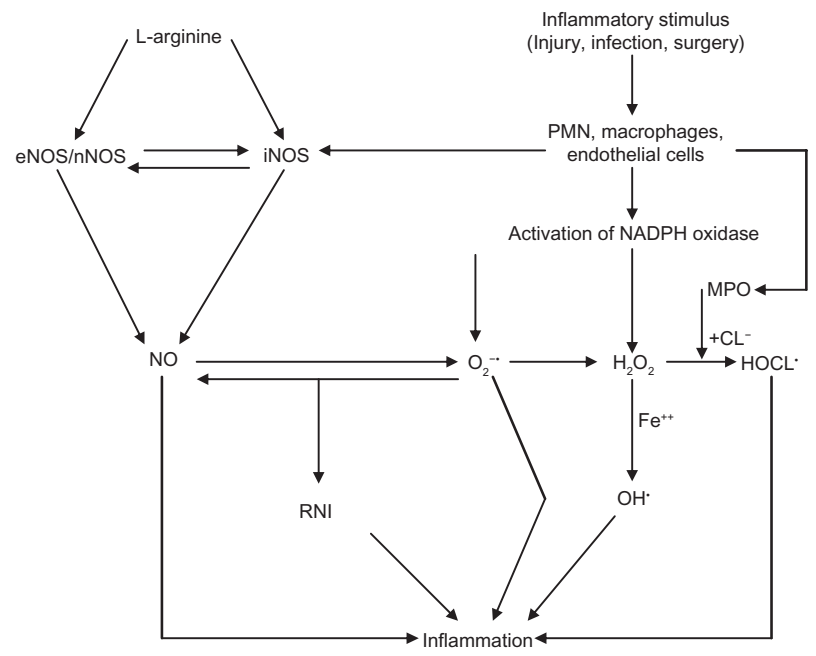

Figure I Scheme showing generation of ROS and NO and formation of RNls. Stimulus could be injury, infection, foreign particles, or release of various proinflammatory cytokines. A close interaction exists between NADPH oxidase and MPO (see the text). Superoxide anion can inactivate NO, and in turn NO can inactivate superoxide anion. $\mathrm{NO}$ and superoxide anion interact to form reactive nitrogen intermediates that are potent inflammatory substances. In general, iNO is proinflammatory, whereas eNO is anti-inflammatory in nature.

Abbreviations: MPO, myeloperoxidase; NADPH, nicotinamide adenine dinucleotide phosphate; PMNLs, polymorphonuclear leukocytes; RNI, reactive nitrogen intermediates; ROS, reactive oxygen species. develop involvement of joints, kidneys, and other organs. Similarly, the response of patients with lupus and rheumatoid arthritis is variable. Some respond, others may not respond, and some show only partial response to the same therapeutic measures. This type of varied presentation(s) and differential response to the same treatment is at times baffling and suggests that the involvement of various organs and tissues due to the underlying inflammatory process is varied, and the degree of involvement may differ in both time and extent and, more importantly, is unpredictable. It is also possible that continued inflammatory events seen in lupus, rheumatoid arthritis (RA), and other rheumatological conditions could be due to failure of the resolution of inflammation. Thus, the balance between inflammation and resolution is disturbed more in favor of proinflammatory events and/or failure of resolution-inducing molecules to be produced at the most appropriate time, leading to nonresolution of inflammation. In other words, even after the inciting agent responsible for the initiation of inflammation is removed, inappropriate inflammation continues simply because resolution failed to occur. This leads to delay in the healing/repair process and so tissue/organ damage continues. This may explain why target organ damage continues even when these patients are continuing to take anti-inflammatory and immunosuppressive medicines. In view of this, it is imperative that administration of proresolution-inducing agents is needed to obtain full remission and restore normal physiological function of the target tissues/organs in these diseases. Such endogenous proresolution-inducing molecules include lipoxins (LXs), resolvins, protectins, maresins, NO, nitrolipids, 15 deoxy $\Delta^{12-14} \mathrm{PGJ}_{2}, \mathrm{PGD}_{2}$, anti-inflammatory cytokines such as IL-4, IL-10, and some polyunsaturated fatty acids (PUFAs). Hence, understanding the interaction(s) between proinflammatory and anti-inflammatory and proresolution molecules is important to devise newer therapeutic strategies in several inflammatory conditions.

\section{Pathobiology of inflammation with specific reference to chronic inflammation}

Inflammation is a reaction to injurious agents, either external or internal, that consists of both vascular and cellular responses. Inflammation may be local or systemic, and it can be acute or chronic. During inflammation, the reaction of blood vessels is unique and leads to the accumulation of fluid and leukocytes in extravascular tissues. This reaction can be in the form of vasodilatation, which is seen as hyperemia at the site(s) of injury and which serves the essential function of increasing the blood supply to the injured tissue/organ so that 
adequate elimination of the inflammation-inducing agent is achieved and/or the repair process can occur after the inflammation subsides. Thus, injury and repair are two faces of the inflammatory process, and it is difficult to separate these two processes. In fact, in the majority of instances, inflammation to injury and repair occur almost simultaneously. ${ }^{1}$

\section{Mediators of inflammation}

Some of the important mediators of inflammation include histamine, serotonin, lysosomal enzymes, PGs, LTs, PAFs, ROS, NO, HOCL, various cytokines, kinin system, coagulation/ fibrinolysis system, and complement system. ${ }^{1}$ The role of arachidonic acid and other PUFAs and their products in inflammation deserves special mention in view of their role in inflammation, resolution of inflammation, and inhibition of production of proinflammatory cytokines, which may be relevant to their involvement in lupus and other rheumatological conditions.

\section{Metabolism of essential fatty acids}

Cis-linoleic acid (LA, 18:2 $\omega$-6) and $\alpha$-linolenic acid (ALA, 18:3 $\omega-3$ ) are essential nutrients because they cannot be synthesized by the human body and are hence called 'essential fatty acids' (EFAs). LA is converted to $\gamma$-linolenic acid (GLA, $18: 3, \omega-6)$ by the action of the enzyme $\Delta^{6}$ desaturase, and GLA is elongated to form dihomo-GLA (DGLA, 20:3, $\omega-6$ ), the precursor of the 1 series of prostaglandins. $\Delta^{6}$ desaturase is the rate-limiting step in the metabolism of EFAs. DGLA can also be converted to arachidonic acid (AA, 20:4, $\omega$ - 6 ) by the action of the enzyme $\Delta^{5}$ desaturase. AA forms the precursor of two series of prostaglandins, thromboxanes, and the four series of leukotrienes (LTs). ALA is converted to eicosapentaenoic acid (EPA, 20:5, $\omega-3$ ) by $\Delta^{6}$ and $\Delta^{5}$ desaturases. EPA forms the precursor of the three series of prostaglandins and the five series of LTs. EPA can be elongated to form docosahexaenoic acid (DHA, 22:6, $\omega-3$ ). AA, EPA, and DHA also form precursors to a group of novel compounds such as LXs, resolvins, protectins, and maresins ${ }^{2-9}$ that exhibit anti-inflammatory action (see Figure 2 for metabolism of EFAs). Eicosanoids bind to G-protein-coupled receptors (GPCRs) on many cell types and mediate virtually every step of inflammation. They are found in inflammatory exudates, and their synthesis is increased at sites of inflammation. Nonsteroidal anti-inflammatory drugs (NSAIDs) such as aspirin inhibit cyclooxygenase (COX) activity and are thus believed to bring about their anti-inflammatory action, though this has been disputed. On the basis of the involvement of eicosanoids in inflammation, COX-2 inhibitors have been developed. However, recent studies showed that COX-2 inhibitors enhance cardiovascular

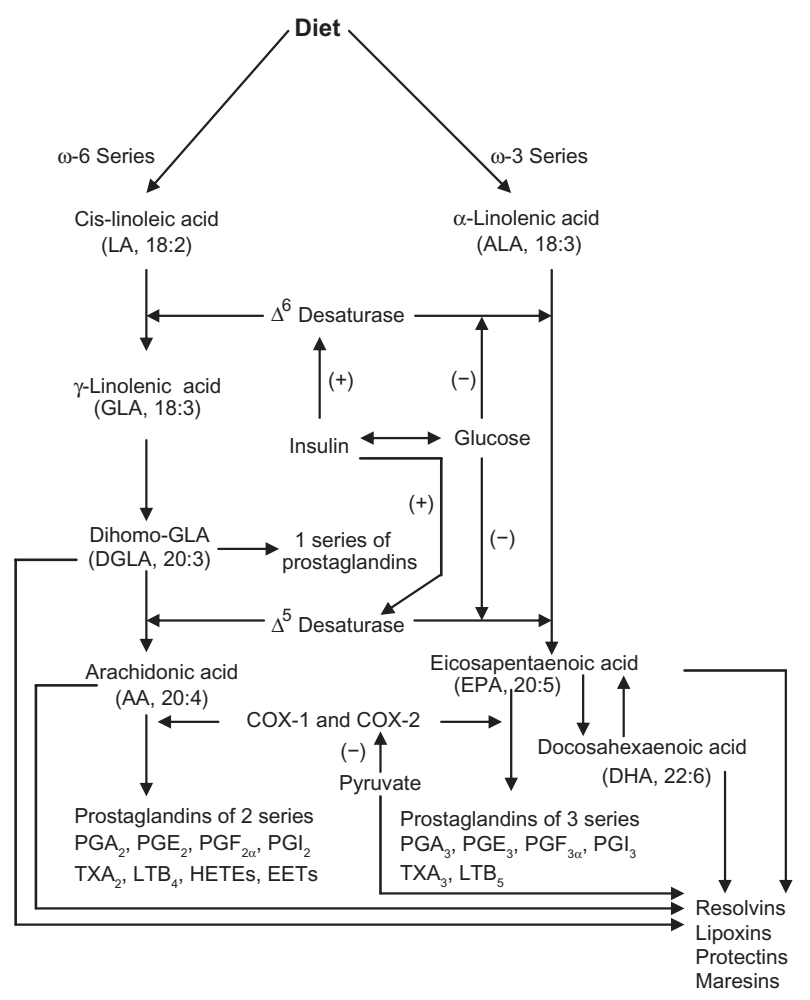

Figure 2 Metabolism of essential fatty acids. Prostaglandins of 3 series are less proinflammatory compared with prostaglandins of 2 series. Resolvins are formed from both EPA and DHA and are known to have anti-inflammatory actions and participate in the resolution of inflammation. EPA can be converted to DHA. DHA can be retroconverted to EPA. (+) indicates increase in the synthesis or action; $(-)$ indicates inhibition of synthesis or action. Insulin augments whereas glucose inhibits the activity of $\Delta^{6}$ and $\Delta^{5}$ desaturases. Pyruvate inhibits COX-2 activity. Insulin increases, whereas glucose decreases the levels of pyruvate.

events, ${ }^{6,10}$ suggesting that there is a close interaction between eicosanoids and cardiovascular system.

\section{Lipoxins, resolvins, protectins, and maresins}

There are two COX enzymes: the constitutively expressed COX-1 and the inducible enzyme COX-2. Different types of PGs are formed by the action of COX enzymes depending on the substrate fatty acid from which they are derived. Different types of PGs exhibit different actions and sometimes diametrically opposite actions. For example, $\mathrm{PGE}_{2}, \mathrm{PGF}_{2 \alpha}$, thromboxane $\mathrm{A}_{2}\left(\mathrm{TXA}_{2}\right)$, and LTs exhibit proinflammatory actions, whereas $\mathrm{PGE}_{1}$ and prostacyclin $\left(\mathrm{PGI}_{2}\right)$ show anti-inflammatory actions. Furthermore, the distributions of COX-1 and COX-2 enzymes have restricted tissue distribution. Platelets contain thromboxane synthetase, and hence $\mathrm{TXA}_{2}$, a potent platelet aggregator and vasoconstrictor, is formed in these cells, whereas vascular endothelial cells possess $\mathrm{PGI}_{2}$ synthetase but lack thromboxane synthetase and thus they mainly form, $\mathrm{PGI}_{2}$, a potent platelet antiaggregator and vasodilator. The balance between $\mathrm{TXA}_{2}$ and $\mathrm{PGI}_{2}$ is important in thrombus formation 
in coronary and cerebral blood vessels. $\mathrm{PGE}_{2}$ is hyperalgesic, causes a marked increase in pain produced by intradermal injection of suboptimal concentrations of histamine and bradykinin, and is involved in cytokine-induced fever during infections. $\mathrm{PGD}_{2}, \mathrm{PGE}_{2}$, and $\mathrm{PGF}_{2 \alpha}$, major metabolites of the COX pathway in mast cells, cause vasodilatation and increase the permeability of postcapillary venules, thus potentiating edema formation. COX-2 enzyme is absent in most tissues under normal 'resting' conditions and is expressed only in response to proinflammatory stimuli, whereas COX-1 is constitutively expressed in most tissues. Thus, PGs produced by COX-1 serve a homeostatic function (such as fluid and electrolyte balance in the kidneys and cytoprotection in the gastrointestinal tract), whereas COX-2 stimulates the production of the PGs that are involved in inflammatory reactions.

There are three types of lipoxygenases and they are present in only a few types of cells. 5-lipoxygenase (5-LO), present in neutrophils, produces 5-HETE, which is chemotactic for neutrophils and is converted into LTs. $\mathrm{LTB}_{4}$, a potent chemotactic and activator of neutrophils, induces aggregation and adhesion of leukocytes to vascular endothelium, generation of ROS, and release of lysosomal enzymes. The cysteinylcontaining $\mathrm{LTs}_{4}, \mathrm{D}_{4}$, and $\mathrm{E}_{4}\left(\mathrm{LTC}_{4}, \mathrm{LTD}_{4}\right.$, and $\left.\mathrm{LTE}_{4}\right)$ induce vasoconstriction, bronchospasm, and vascular permeability in venules. LTs are more potent than histamine in increasing vascular permeability and causing bronchospasm. LTs mediate their actions by binding to cysteinyl leukotriene 1 (CysLT1) and CysLT2 receptors.

LXs are generated from AA, EPA, and DHA by transcellular biosynthetic mechanisms involving two cell populations. Neutrophils produce intermediates in LX synthesis, and these are converted to LXs by platelets interacting with leukocytes. $\mathrm{LXA}_{4}$ and $\mathrm{LXB}_{4}$ are generated by the action of platelet 12-lipoxygenase on neutrophil-derived LTA $_{4}$. LXs inhibit leukocyte recruitment, neutrophil chemotaxis, and adhesion to endothelium. ${ }^{7}$ LXs have a negative regulation on LT synthesis and action and help in the resolution of inflammation. An inverse relationship generally exists between LXs and LTs, and the balance between these two molecules appears to be crucial in the determination of degree of inflammation and its final resolution (see Figures 3-7 for the formation of LXs, resolvins, and protectins).

\section{Aspirin-triggered I 5 epimer LXs, resolvins, and protectins}

Aspirin-triggered 15 epimer LXs (ATLs) are potent counterregulators of polymorphonuclear neutrophils(PMNs)-mediated injury and acute inflammation. Acetylated COX-2 enzyme of endothelial cells generates 15R-hydroxyeicosatetraenoic acid (15R-HETE) from AA that is converted by activated PMNs to the 15-epimeric LXs that have potent anti-inflammatory properties. $^{2-11}$ This cross-talk between endothelial cells and PMNs, leading to the formation of 15R-HETE and its subsequent conversion to 15 -epimeric LXs by aspirin-acetylated COX-2, is a protective mechanism to prevent local inflammation on the vessel wall by regulating the motility of PMNs, eosinophils, and monocytes. ${ }^{9}$ Endothelial cells also oxidize AA, EPA, and DHA via P450 enzyme system to form various hydroxyeicosatetraenoic acids and epoxyeicosatrienoic acids such as 11,12-epoxy-eicosatetraenoic acid(s) that have many biological actions, including blocking endothelial cell activation, whereas nonenzymatic oxidation products of EPA inhibit phagocyte-endothelium interaction and suppress the expression of adhesion molecules ${ }^{6,12-17}$ (see Figure 8 for the formation of isoprostane-like compounds formed from EPA). The anti-inflammatory activity of EPA and its derivatives such as isoprostane-like compounds is supported by the observation that when hospitalized patients of acute guttate psoriasis with a minimum $10 \%$ of body surface area involvement (range 10\%-90\%) were given an n-3 fatty acid-based lipid emulsion (100 mL/day with $2.1 \mathrm{~g}$ EPA and $21 \mathrm{~g} \mathrm{DHA}$ ) for 10 days, the severity of disease markedly decreased in all the patients. In these patients, platelet-activating factor (PAF) generation in ionophore-stimulated neutrophils on days 0,1 , $3,5,10$, and 40 decreased, and a more than tenfold increase in neutrophil EPA-derived 5-LO product formation ( $\mathrm{LTB}_{5}$, its omega-oxidation products, nonenzymatic degradation products of LTA5, and 5-hydroxyeicosapentaenoic acid) was noted in the n-3 group. These results conclusively suggest that modulation of eicosanoid metabolism by intravenous

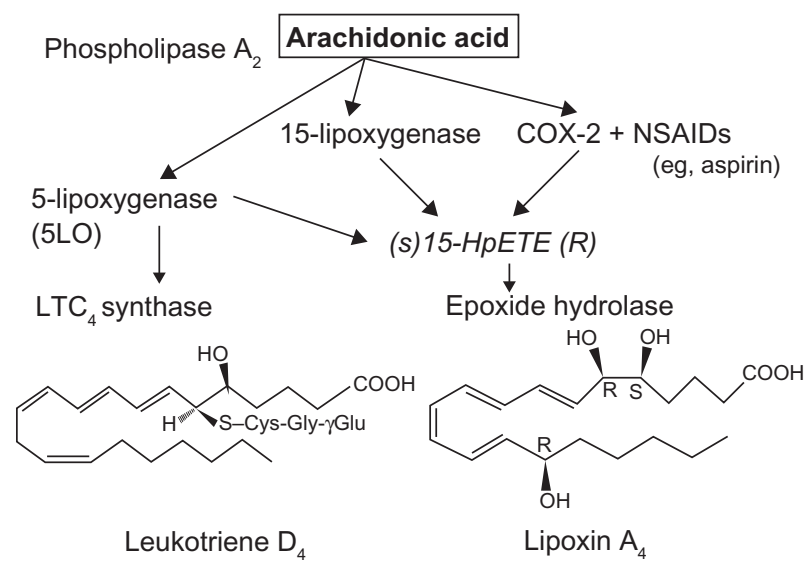

Figure 3 Scheme showing formation of lipoxin $A_{4}$ from arachidonic acid. Abbreviation: NSAIDs, nonsteroidal anti-inflammatory drugs. 


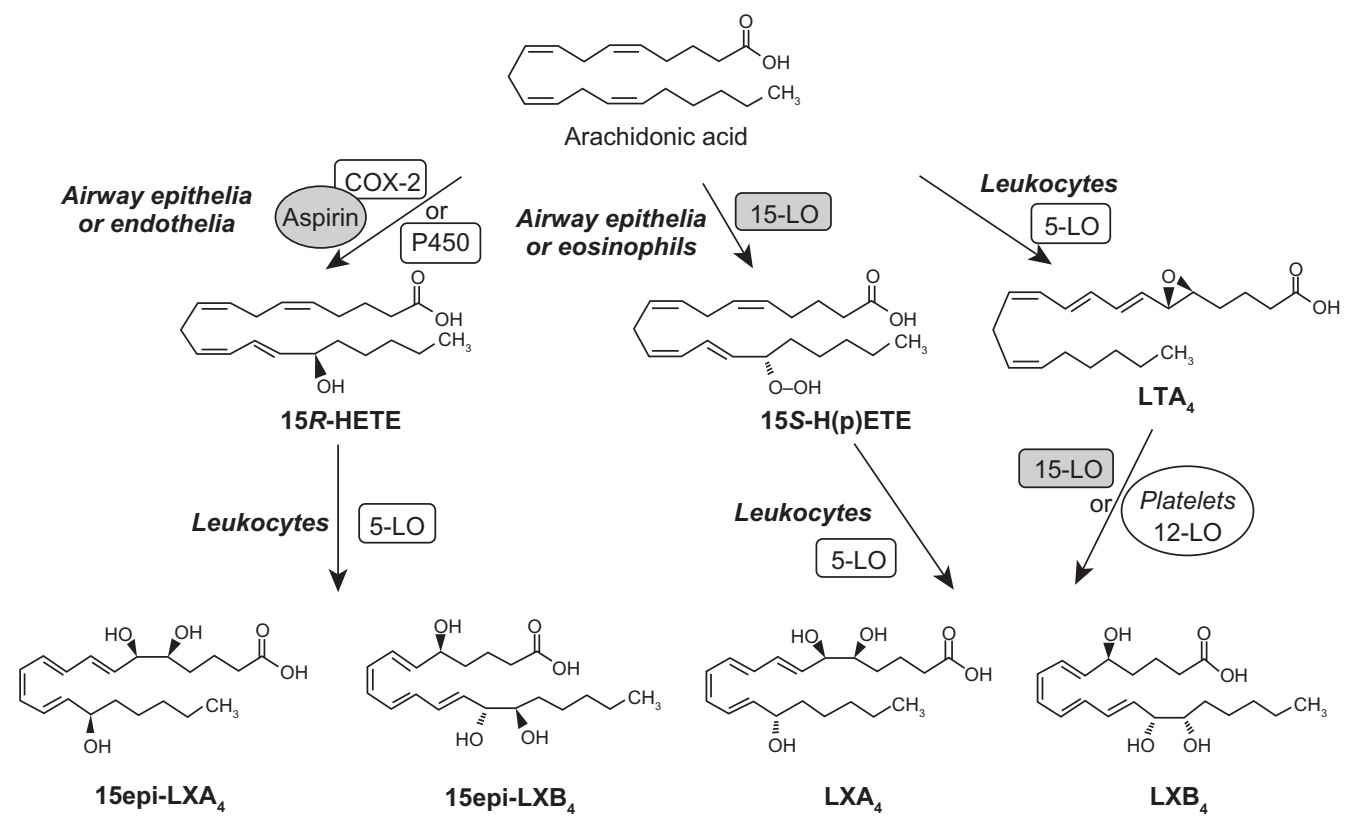

Figure 4 Scheme showing the formation of various lipoxins from arachidonic acid as a result of intercellular communication, coordination, and cooperation.

n-3 fatty acid supplementation exerts a rapid beneficial effect on inflammation by forming nonenzymatic isoprostane-like compounds. ${ }^{18}$

It is likely that similar isoprostane-like compounds may also be formed from DHA. However, this needs to be firmly established.
Akin to the formation of 15R-HETE and 15-epimeric LXs from AA, similar compounds are also formed from EPA and DHA. In the presence of aspirin, activated COX-2 of human endothelial cells converts EPA to 18R-HEPE, 18-HEPE, and 15R-HEPE. Activated human PMNs in turn converted 18RHEPE to 5,12,18R-triHEPE and 15R-HEPE to 15-epi-LXA

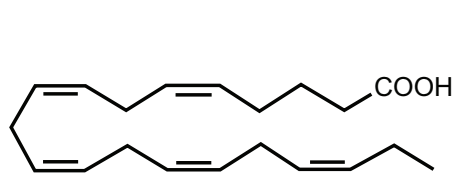

Eicosapentaenoic acid<smiles>[R20]C/C=C\C/C=C\C=C/[C@H](O)CCCC(=O)O</smiles><smiles>[R17]CCCCCC(=O)O</smiles>
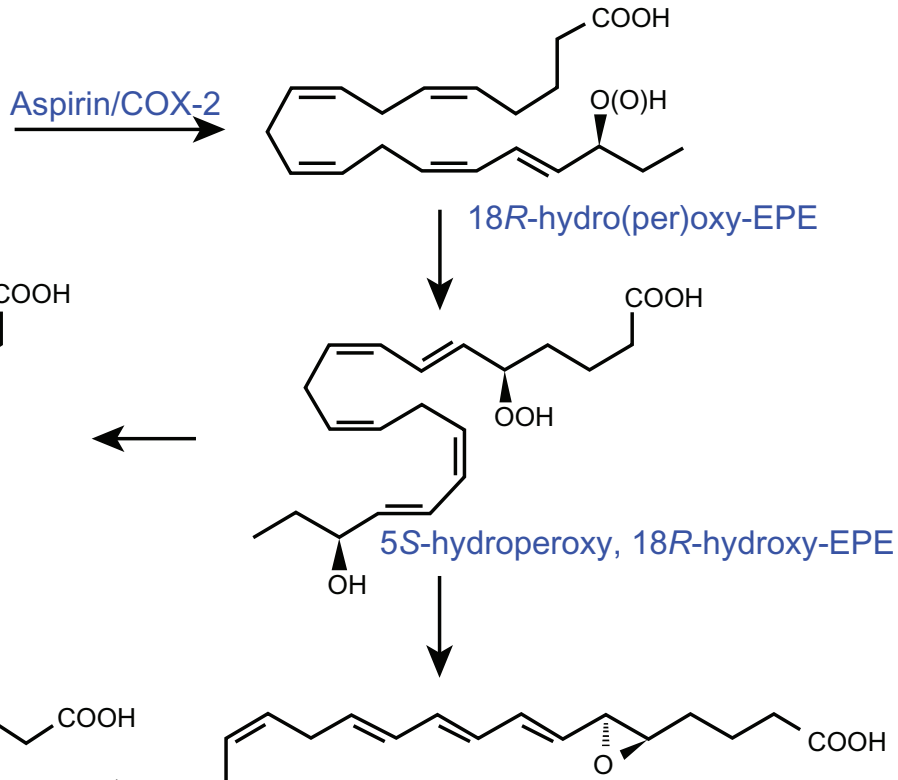

5,6-epoxy, 18R-hydroxy-EPE

Figure 5 Scheme showing the formation of resolvin $E_{1}$ from EPA. 


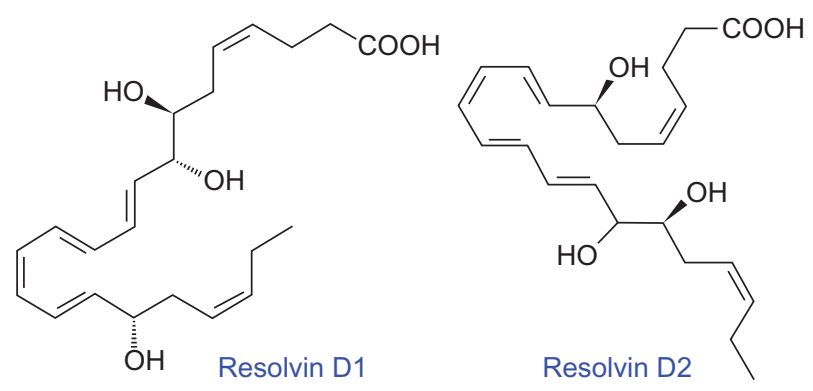

Figure 6 Structures of resolvins formed from docosahexaenoic acid.

by their 5-LO. Both 18R-HEPE and 5,12,18R-triHEPE inhibited $\mathrm{LTB}_{4}$-stimulated PMN transendothelial migration. 5,12,18R-triHEPE effectively competed with $\mathrm{LTB}_{4}$ for its receptors and inhibited PMN infiltration, suggesting that it suppresses LT-mediated responses at the sites of inflammation (reviewed in Das $^{6}$ and Serhan et al ${ }^{19,20}$ ).

The conversion of EPA by human endothelial cells with upregulated COX-2 treated with ASA of EPA to 15-epi-LX, also termed aspirin-triggered LX (ATL), and to 18R-hydroxyeicosapentaenoic acid (HEPE) and 15R-HEPE is interesting. These compounds in turn are used by PMNLs to generate separate classes of novel trihydroxy-containing mediators, including 5 -series $15 \mathrm{R}$ LX(5) and 5,12,18R-triHEPE, which are potent inhibitors of human PMNL transendothelial migration and infiltration in vivo (ATL analogue $>5,12,18 \mathrm{R}$-triHEPE $>18 \mathrm{R}$-HEPE). Acetaminophen and indomethacin also permitted 18R-HEPE and 15R-HEPE generation with recombinant COX-2. The formation of these bioactive lipid mediators via COX-2NSAID-dependent oxygenations and cell-cell interactions may have significant therapeutic benefits in inflammation, neoplasia, and vascular diseases. ${ }^{19,20}$

Murine brain cells expressing COX-2 and treated with aspirin transformed enzymatically DHA to $17 \mathrm{R}$ series of

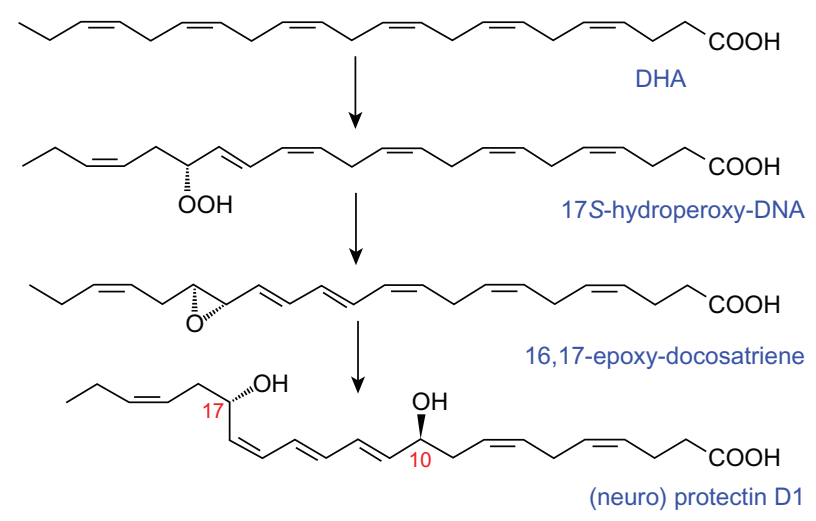

Figure 7 Scheme showing the formation of neuroprotectin $D_{1}$ (protectin $D_{1}$ ) from docosahexaenoic acid. hydroxy DHAs (HDHAs), which, in turn, is converted enzymatically by PMNs to di- and trihydroxy-containing docosanoids. ${ }^{19-22}$ DHA is converted by leukocytes, brain, and glial cells to 17S-hydroxy-containing docosanoids denoted as docosatrienes (the main bioactive member of the series was $10,17 \mathrm{~S}$-docosatriene) and $17 \mathrm{~S}$ series resolvins, and they serve as regulators of both leukocytes, reducing infiltration in vivo, and glial cells, blocking their cytokine production. These results indicate that DHA is the precursor to potent protective mediators generated via enzymatic oxygenations to novel docosatrienes and $17 \mathrm{~S}$ series resolvins that have significant anti-inflammatory action and participate in the resolution of inflammatory events (see Figures 2-6 for the formation of LXs, resolvins, and protectins from their precursors and structures).

Similar small-molecular-weight compounds are also generated from AA, EPA, and DHA: 15R-hydroxylcontaining compounds from AA, 18R series from EPA, and 17R-hydroxy series from DHA. All these compounds have potent anti-inflammatory actions and resolve inflammation and hence are called 'resolvins.' Resolvins inhibited cytokine generation, leukocyte recruitment, leukocyte diapedesis, and exudate formation. The formation of resolvins from AA, EPA, and DHA and from acetylated COX-2 is generated via transcellular biosynthesis (eg, due to cell-cell communication between endothelial cells and PMNs), and their main purpose appears to be to suppress inflammation. Resolvins inhibited brain ischemia-reperfusion injury. ${ }^{21,22}$ It is possible that LXs, resolvins, and protectins (docosanoids are also called as protectins because they have neuroprotective actions) behave as endogenous anti-inflammatory and cytoprotective molecules. The general cytoprotective properties that have been attributed to AA, EPA, and DHA can be related to their conversion to LXs, resolvins, and docosanoids (protectins). Hence, any defect in the synthesis of LXs, resolvins, and protectins or their inappropriate degradation could lead to perpetuation of inflammation. This could be one mechanism by which acute inflammation assumes its chronic phase as seen in lupus and other rheumatological conditions.

In addition, continued production of proinflammatory molecules such as macrophage MIF and HMGB-1 seems to have a significant role in the pathobiology of lupus and other conditions. It is possible that both MIF and HMGB-1 are able to overcome the anti-inflammatory actions of LXs, resolvins, protectins, and maresins. Alternatively, inadequate production of LXs, resolvins, protectins, and maresins may fail to suppress the production of MIF and 
A

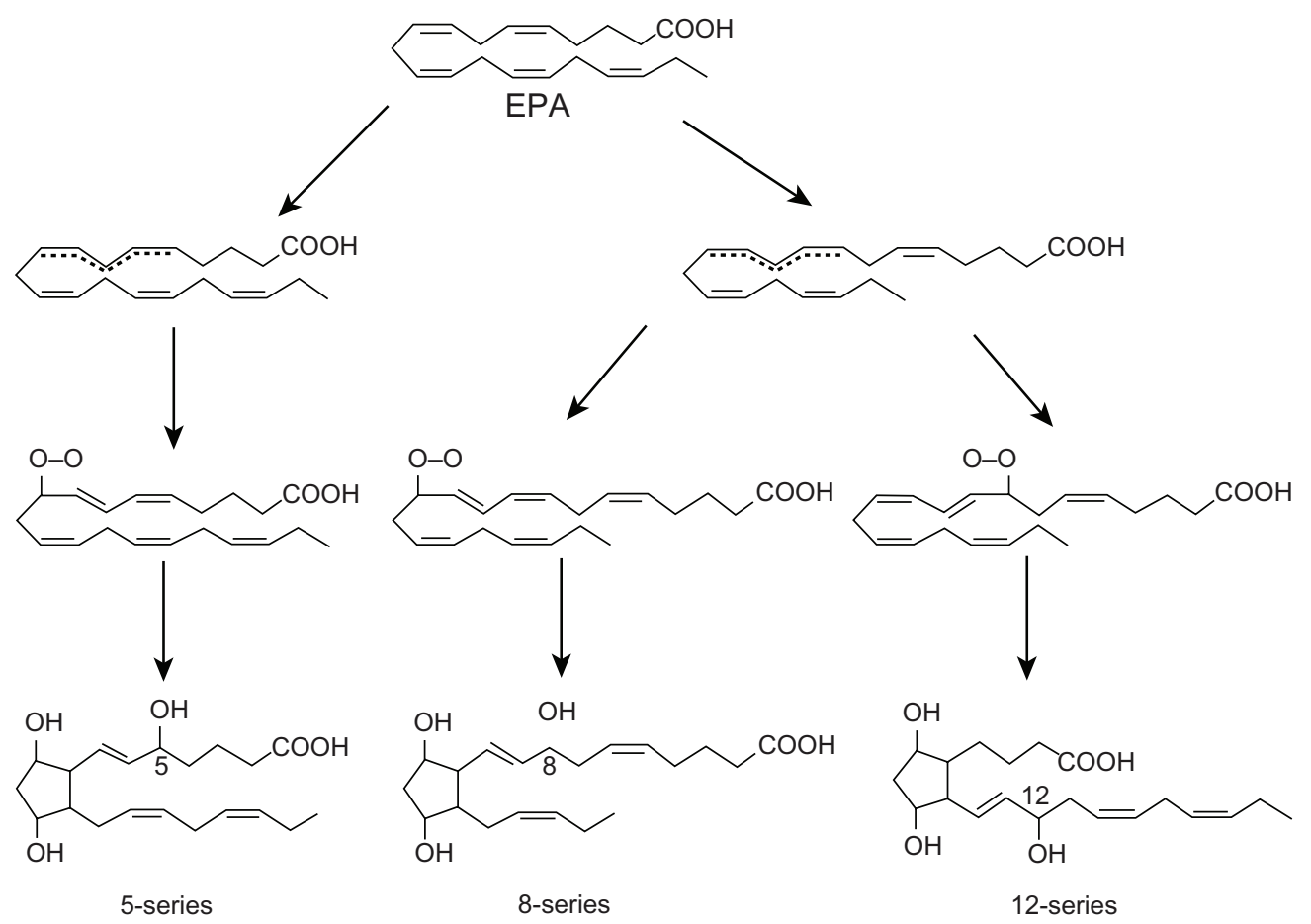

B
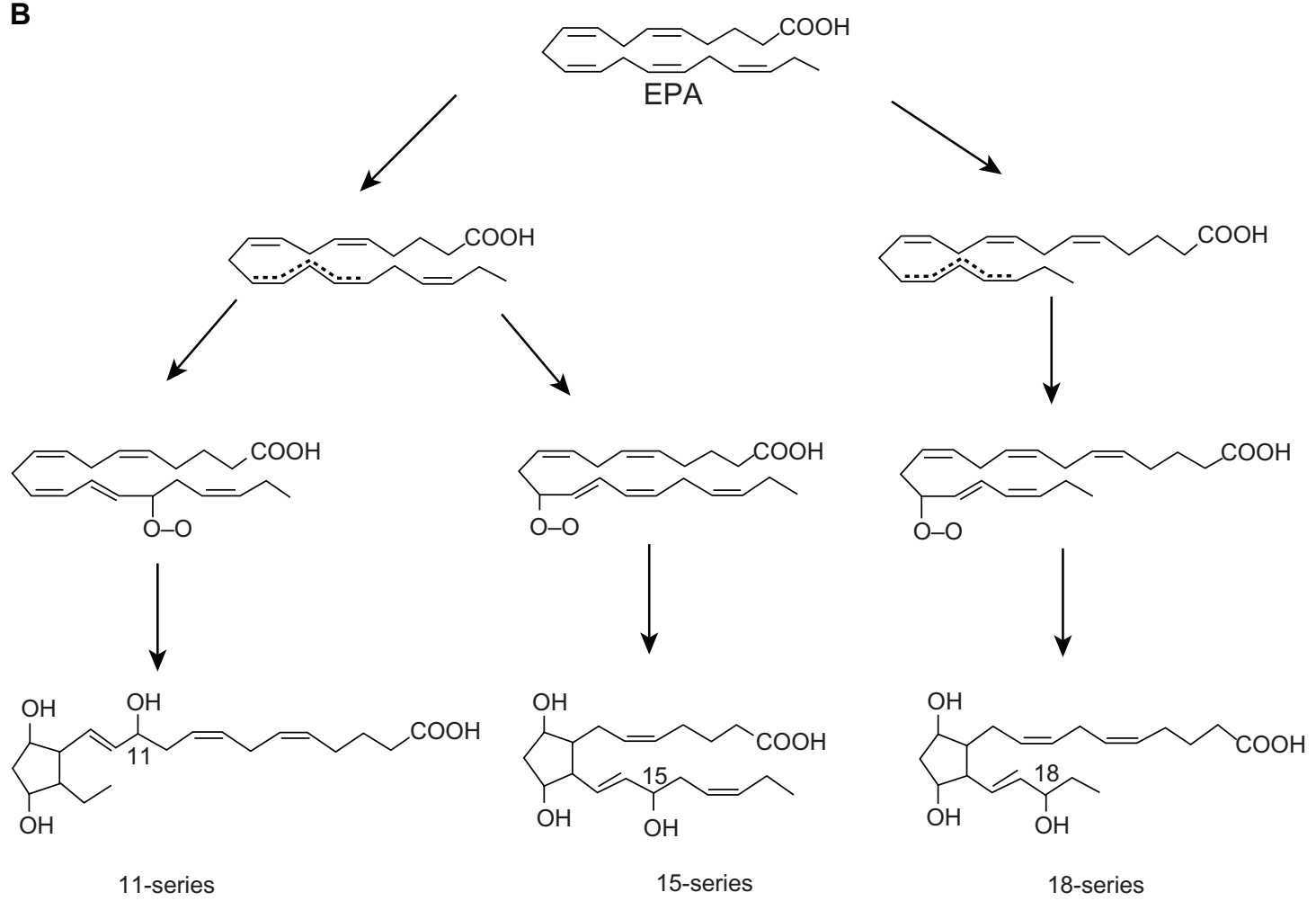

Figure 8 A) and B) Scheme showing the formation of nonenzymatic isoprostane-like compounds that exhibit anti-inflammatory actions.

HMGB-1, which may allow the inflammatory process to continue.

In this context, it is noteworthy that anti-inflammatory cytokines IL-4 and IL-10 may have the ability to trigger the conversion of AA, EPA, and DHA to LXs, resolvins, protectins, and maresins, suggesting a mechanism by which they are able to suppress inflammation. ${ }^{23}$ For example, it was shown that IL-4 upregulated 15-LO gene expression in human leukocytes. (It may be noted here that 15-S-HETE (a 15-LO product; $\mathrm{LO}=$ lipoxygenase enzyme) and LXs (interaction 
products between 5-LO and either 12-LO or 15-LO) counteract the proinflammatory actions of LTs.) Glomerular 12/15-LO mRNA increased significantly over controls 24 and $48 \mathrm{~h}$ after nephrotoxic serum injection then decreased at $72 \mathrm{~h}$. RNA from nephrotoxic-serum-injected glomeruli contained higher levels of 12/15-LO mRNA than that from unstimulated peripheral leukocytes, suggesting that 12/15-LO transcription is upregulated locally in native and/or infiltrating glomerular cells. Glomerular IL-4 mRNA increased markedly 16 $\mathrm{h}$ post-nephrotoxic serum injection, and was then reduced, suggesting a potential role for T-cell-derived IL-4 in directing the expression of 12/15-LO during glomerulonephritis. This suggested tandem-regulated in vivo gene expression for IL-4 and LO, both of which promote counterinflammatory influences in immune complex-mediated injury.

The 5-lipoxygenated metabolites of AA, the LTs, are major mediators of early glomerular hemodynamic and structural deterioration during experimental glomerulonephritis, which is generated largely by infiltrating leukocytes but can also occur by intrinsic glomerular cells via transcellular metabolism of intermediates. In animal models of glomerulonephritis and other renal pathologic states, LTs have been shown to exert adverse effects in the glomerulus. $\mathrm{LTB}_{4}$ augments neutrophil infiltration, and $\mathrm{LTC}_{4}$ and $\mathrm{LTD}_{4}$ mediate potent vasoconstrictor effects on the glomerular microcirculation. Selective blockade of the 5-LO pathway produced a significant amelioration of the deterioration of renal hemodynamic and structural parameters. On the other hand, 15-S-hydroxyeicosatetraenoic acid (15-S-HETE), the immediate product of arachidonate 15-lipoxygenase, and the LXs, which are produced by sequential 15- and 5- or 5- and 12-lipoxygenation of AA, are also generated in the course of glomerular injury that antagonizes LT-induced neutrophil chemotaxis, and lipoxin A4 antagonizes the effects of LTD4 and LTC4 on the glomerular microcirculation. Thus, the contrasting effects of 5- and 15-lipoxygenase products represent endogenous pro- and anti-inflammatory influences that ultimately determine and regulate the extent and severity of glomerular inflammation..$^{24-27}$

These results are in favor of the proposal that antiinflammatory cytokines IL-4 and IL-10 induce the expression and synthesis of anti-inflammatory lipid mediators such as LXs, resolvins, protectins, and maresins in addition to their ability to suppress the production of proinflammatory cytokines such as IL-2, IL-6, TNF- $\alpha$, MIF and HMGB-1, and LTs.

It is also relevant to note that monocytes and macrophages express an extensive repertoire of GPCRs that regulate inflammation and immunity.
A number of GPCRs (eg, Edg5, P2ry2, and 6 ) have been reported to be expressed by macrophages and two cell types closely related to macrophages (osteoclasts and dendritic cells), whereas Gpr84 expression was largely restricted to macrophage populations and granulocytes. ${ }^{28}$ It is now apparent that many PUFAs, especially AA, EPA, and DHA, and their metabolites, such as eicosanoids, LXs, resolvins, protectins, and maresins, also function directly as agonists at a number of GPCRs. Tissue distribution studies and siRNA knockdown experiments have indicated key roles for these GPCRs in glucose homeostasis, adipogenesis, leukocyte recruitment, and inflammation. ${ }^{29} \mathrm{~A}$ recent study showed that the GPCR120 functions as a $\omega-3$ fatty acid receptor/sensor. Stimulation of GPR120 with $\omega$-3 fatty acids (EPA and DHA) induced broad anti-inflammatory effects in monocytic RAW 264.7 cells and in primary intraperitoneal macrophages. All of these effects were abrogated by GPR120 knockdown. The $\omega-3$ fatty acid treatment not only inhibited inflammation but also enhanced systemic insulin sensitivity in wildtype mice, but was without effect in GPR120 knockout mice. These results suggest that GPR120 is a functional $\omega-3$ fatty acid receptor/sensor and mediates potent insulin-sensitizing and antidiabetic effects in vivo by repressing macrophage-induced tissue inflammation. ${ }^{30}$ Thus, it is likely that PUFAs and their anti-inflammatory products such as LXs, resolvins, protectins, and maresins inhibit the production of various proinflammatory molecules, including MIF and HMGB-1, and thus suppress inflammation in diseases such as lupus and RA.

In view of the role of MIF and HMGB-1 in lupus and RA and their interaction with corticosteroids, a brief discussion of their role in lupus and RA is given below.

\section{Macrophage MIF}

Macrophage MIF is a potent proinflammatory molecule produced by T-cells, macrophages, pituitary, adrenal, liver, spleen, lung, and skin, and its expression correlates with macrophage functions such as adherence, spreading, phagocytosis, and tumoricidal action. MIF is a modulator of inflammatory and immune responses..$^{31} \mathrm{MIF}$ released by anterior pituitary cells counteracts the effects of glucocorticoids and serves as an integral part of the host's stress response. Pituitary production of MIF is induced by corticotrophinreleasing factor in a cyclic AMP-dependent manner. MIF is present within the intracellular pools of macrophages and hence is released rapidly in response to stimulation. MIF promotes TNF- $\alpha$, IL-1 $\beta$, IL-2, IL-6, IL-8, IFN- $\gamma$, and NO release, enhances matrix metalloproteinase expression, and 
induces COX-2 pathway. TNF- $\alpha$ production is reduced by antisense MIF treatment of macrophages, and MIF is a potent stimulant of TNF- $\alpha$ production. Glucocorticoids stimulate the release of MIF, which can override the immunosuppressive effects of glucocorticoids, suggesting that MIF acts in concert with glucocorticoids to control the 'set point' of the immune and inflammatory response. MIF has a role in the development of $\mathrm{T}_{\mathrm{H}}$ 2-driven antibody production and is one of the mediators of sepsis and septic shock because neutralizing anti-MIF antibodies protect experimental animals from severe sepsis. ${ }^{32-41}$ MIF knockout mice are relatively resistant to LPS-induced sepsis.

In lupus and other rheumatological conditions, a good correlation has been found between the severity of the disease and plasma MIF levels. In those who showed successful immunosuppression, MIF production became negative, ${ }^{35}$ suggesting that plasma MIF levels could be used as a marker of response to therapy. It was reported that plasma levels of MIF were increased in those with active lupus and RA, indicating that MIF plays a key role in these diseases. ${ }^{42-46}$

\section{HMGB- I}

HMGB-1 is a nonhistone nuclear protein that is constitutively expressed in quiescent cells and stored in the nucleus. It is one of the most evolutionarily preserved proteins in eukaryocytes and has been implicated in many cellular functions, including binding of transcription factors to their cognate DNA sequences. In addition to the nucleus, HMGB-1 is also localized to the cell membrane, where it colocalizes and interacts with the receptor for advanced glycation end products (RAGE) and toll-like receptor-4 (TLR-4) and is released by activated macrophages/monocytes and functions as a late mediator of lethal endotoxemia and sepsis. ${ }^{38,39}$ Following stimulation, endotoxin, TNF- $\alpha$, IL- $1 \beta$, IFN- $\gamma$ macrophages, monocytes, and pituitary cells release HMGB-1 in a time- and dose-dependent fashion. HMGB-1 is also released passively from necrotic or damaged cells and after tissue ischemia and reperfusion injury. Apoptotic cells do seem to release HMGB-1. Because autoantibodies against double-stranded DNA (dsDNA) and nucleosomes represent a hallmark of lupus, it has been suggested that impaired phagocytosis of apoptotic cells with consecutive release of nuclear antigens may contribute to the immune pathogenesis. The architectural chromosomal protein and HMGB-1 are tightly attached to the chromatin of apoptotic cells. HMGB-1 bound to nucleosomes released from late apoptotic cells in vitro and HMGB-1nucleosome complexes were also detected in plasma from lupus patients. HMGB-1-containing nucleosomes from apop- totic cells induced secretion of IL-1 $\beta$, IL-6, IL-10, and TNF- $\alpha$ and expression of costimulatory molecules in macrophages and dendritic cells (DCs), respectively. HMGB-1-containing nucleosomes from apoptotic cells induced anti-dsDNA and antihistone IgG responses in a toll-like receptor (TLR)-2dependent manner, whereas nucleosomes from living cells did not. Thus, HMGB-1-nucleosome complexes activate antigenpresenting cells and contribute to the pathogenesis of lupus via breaking the immunological tolerance against nucleosomes/ dsDNA. ${ }^{47}$ Furthermore, HMGB-1stimulates macrophages, monocytes, and neutrophils to release the proinflammatory cytokines TNF, IL-1, IL-6, IL-8, and macrophage inflammatory protein-1. Thus, there is a close interaction between TNF, ILs, TLRs, and HMGB-1. Human microvascular endothelial cells are stimulated by HMGB-1 to increase their expression of ICAM-1, VCAM-1, TNF, and chemokines such as IL-8, suggesting that HMGB-1 can propagate the inflammatory response in the endothelium during infection and injury.

Anti-HMGB-1 antibodies protected mice against lethal endotoxemia in a dose-dependent fashion. Ethyl pyruvate (EP), stearoyl lysophosphatidylcholine, nicotine, and green tea extract significantly attenuated endotoxin-induced HMGB-1 release and protected animals from endotoxininduced lethal sepsis. Neutralizing antibodies against IFN- $\gamma$, a cytokine that is capable of stimulating HMGB-1 release, significantly reduced circulating HMGB-1 levels in septic rats and protected animals from lethal sepsis. ${ }^{48}$ All the enumerated actions of HMGB-1 suggest that it is a proinflammatory molecule and hence may have a role in lupus and RA.

It was reported that patients who developed autoantibodies and/or lupus after treatment with procainamide or other drugs (drug-induced lupus) showed a high prevalence of antibodies to the nucleosomal core high-mobility-group proteins such as HMGB-1. ${ }^{49}$ It was reported that the expression of HMGB-1 in the epidermis and dermis and an increase in the levels of TNF- $\alpha$ and IL-1 $\beta$ were reported in the dermal infiltrates of lesional skin. The high amount of extracellular HMGB-1 observed in skin lesions in lupus indicates that HMGB-1 is involved in the inflammatory process of cutaneous lupus $^{50}$ and, possibly, TNF- $\alpha$ and IL-1 $\beta$ may form a proinflammatory loop with HMGB-1, as they can induce the release of each other. In addition to HMGB-1, increased expression of TNF- $\alpha$ and IL- $1 \beta$ was noted in these dermal lesions, suggesting that extracellular and cytoplasmic HMGB-1 coincides with the clinically most active phase of cutaneous lupus. ${ }^{51}$ Because HMGB-1 can augment expression of TNF- $\alpha$ and IL- $1 \beta$, and the latter can stimulate HMGB-1 formation, it is likely that a proinflammatory loop 
between HMGB-1, TNF- $\alpha$, and IL-1 $\beta$ operates, which could be responsible for the prolonged and sustained inflammation in cutaneous lupus. These results, coupled with the observation that plasma levels of HMGB-1 are increased in patients with active lupus, indicate an active role for HMGB-1 in lupus and other rheumatological conditions.

\section{Inflammatory and anti-inflammatory molecules and antioxidants in lupus}

Thus, lupus, RA, and other rheumatological conditions are characterized by increased production of IL-1, IL-6, TNF- $\alpha$, IFN- $\gamma$, MIF, HMGB-1, iNO, ROS, various chemokines, MPO, GM-CSF, G-CSF, endothelin, and hs-CRP. ${ }^{52-58}$ On the other hand, the concentrations of $\mathrm{PGI}_{2}, \mathrm{PGE}_{1}$, eNO, and antioxidants such as superoxide dismutase (SOD) and glutathione peroxidase are decreased, whereas those of lipid peroxides are increased. ${ }^{52,59-61}$ It is likely that IL-1, IL-6, TNF- $\alpha$, IFN- $\gamma$, HMGB-1, and MIF are released in large amounts in lupus and RA by activated neutrophils, macrophages, T-cells, synovial cells, fibroblasts, and endothelial cells not only to initiate the inflammatory process but also to perpetuate the inflammation. ${ }^{52}$ In addition, IL-1 increases the production by endothelial cells of endothelin-1, which is a potent vasoconstrictor that could lead to Raynaud's phenomena seen in lupus and other collagen vascular conditions such as scleroderma. ${ }^{62}$ Furthermore, IL-2 stimulates the production of autoantibodies and worsens immune-mediated diseases. ${ }^{63}$ Cytokines including IL-6 and CSF-1 (colony stimulating factor-1) initiate immune response, induce cell proliferation, augment matrix-degrading protease activity, and cause resorption of bone (osteoporosis). Proteases released by activated neutrophils are responsible for bone erosions that are more common in RA than in lupus.

At the same time, certain anti-inflammatory molecules are produced that try to contain the inflammatory process and induce resolution of the disease process. For instance, TGF- $\beta$ downregulates inflammation. Various cells, including monocytes, fibroblasts, platelets, and synovial tissue, produce it. TGF- $\beta$ suppresses IL-1-stimulated collagenase transcription (reviewed in Das ${ }^{52}$ ). TGF- $\beta$ counters the degradation of cartilage induced by IL-1 and other cytokines, ${ }^{64}$ inhibits the growth of capillary endothelial cells, suppresses IL-1- and IL-2-dependent T-cell proliferation, inhibits free radical generation by human monocytes, and participates in wound healing and fracture repair. ${ }^{52}$ This suggests that TGF- $\beta$ negatively regulates all the destructive and proinflammatory actions of IL-1, IL-2, TNF- $\alpha$, HMGB-1, and MIF that are important to initiate the repair process and restore normalcy in lupus and other collagen vascular conditions. In contrast, excess production of TGF- $\beta$ provokes and perpetuates fibroblast proliferation, leading to abnormal sclerosis in the skin and internal organs in scleroderma and in the kidney in lupus. This leads to late-stage complications in these conditions. Thus, TGF- $\beta$ is a double-edged sword. When present in subnormal amounts, inflammation may go unchecked, and higher amounts may provoke abnormal sclerosis as seen in scleroderma. ${ }^{65}$ Hence, it is important to maintain normal amounts of TGF- $\beta$ at a given site for normal physiology.

\section{Immune dysfunction in lupus}

Studies focused on cytokines and T-helper cells in the peripheral blood in patients with lupus have revealed inconsistent results that have led to confusion about the exact role of $\mathrm{T}_{\mathrm{H}} 1$ and $\mathrm{T}_{\mathrm{H}} 2$ cells in lupus. ${ }^{66-70}$ In this context, it may be noted that activation of T-cells occurs at the site of disease involvement, and so peripheral plasma measurement of cytokines may not reflect the actual type of T-cells that are actively participating in the disease. In lupus, kidney biopsy is ideal in order to study intrarenal lymphocyte activation. Recently, measurement of messenger RNA (mRNA) expression in urinary sediment has been described, ${ }^{71}$ and it was shown that urinary mRNA and protein expressions of T-bet were significantly higher in lupus with active nephritis compared with those with inactive disease. In contrast, the urinary and protein expressions of GATA-3 were significantly lower in lupus patients with active nephritis. Furthermore, tubular expressions of T-bet and GATA-3 significantly correlated with the histological activity index, ${ }^{72}$ suggesting that active lupus nephritis is associated with increased T-bet and decreased GATA-3 expression in the urinary sediment and kidney tissue and indicating a predominant $\mathrm{T}_{\mathrm{H}} 1$ type of T-lymphocyte activation. It is relevant to note that $\mathrm{T}$-bet promotes $\mathrm{T}_{\mathrm{H}} 1$ lineage commitment and forms an autoregulatory positive-feedback loop with IFN- $\gamma$ to maintain a $\mathrm{T}_{\mathrm{H}} 1$-mediated immune response, ${ }^{73}$ whereas GATA-3 promotes $\mathrm{T}_{\mathrm{H}} 2$ differentiation and induces $\mathrm{T}_{\mathrm{H}} 2$ cytokine production. ${ }^{74}$ Thus, the relative expression of T-bet and GATA-3, resulting in a swing in the $\mathrm{T}_{\mathrm{H}} 1$ and $\mathrm{T}_{\mathrm{H}} 2$ expressions, would ultimately determine the type of T-helper cell expression. These results suggest that measurement of T-helper cell transcription factor gene expression is helpful in the assessment and risk stratification of lupus patients.

\section{Loss of self-tolerance in lupus}

In rheumatological conditions, the presence of diverse autoantibodies directed against a variety of intra- and extracellular components before the development of the 
disease $^{75}$ suggests that normal physiologic mechanisms that maintain tolerance to self-antigens have been breached. A subpopulation of T-cells known as Tregs establishes and preserves self-tolerance, ${ }^{76}$ and so the existence of defective helper and suppressor cells with defective signaling cascades could result in autoantibody generation by forbidden B-cell clones and lead to impaired effector functions in lupus. ${ }^{77}$ These effector dysfunctions are a result of skewed expression of various effector molecules including CD40 ligand (eg, CD154) and various cytokines and may reflect an imbalance of gene expression. Impaired effector T-cells' function as a result of skewed cytokine production creates a microenvironment that facilitates a strong $\mathrm{T}_{\mathrm{H}} 2$ response relative to $\mathrm{T}_{\mathrm{H}} 1$ and Treg activity, which leads to overproduction of IL-4, IL-6, and IL- 10 by $_{\mathrm{H}} 2$ and underproduction of IL-2, IL-12, TGF- $\beta$, and IFN- $\gamma$ by $\mathrm{T}_{\mathrm{H}} 1$ and Tregs. That results in imbalanced autocrine and paracrine effects on $\mathrm{T}$ - and B-cells in the microenvironment. This imbalance in the cytokine production and reduced numbers of $\mathrm{CD} 4^{+} \mathrm{CD} 25^{+}$ Tregs results in insufficient suppressor activity in lupus, which results in dysregulated immune response driving both physiologic and forbidden B-cell clones to overproduce antibodies and autoantibodies. That results in hypergammaglobulinemia. These events occur despite the existence of other counter-regulatory mechanisms, including expression of the cell surface molecule cytotoxic T-lymphocyte antigen 4 (CTLA4). ${ }^{78}$ Studies with IL-2 ${ }^{-/-}$and IL-2R ${ }^{-/}$ knockout mice revealed that IL-2 serves as a third signal that stimulates clonal expansion of effector cells to promote tolerogenic responses and to regulate development and function of $\mathrm{CD}^{+} \mathrm{CD} 25^{+}$Tregs and $\mathrm{CD} 8^{+}$Tregs to maintain tolerance. ${ }^{79,80}$ It was noted that the frequency of CD $4^{+} \mathrm{CD} 25^{+}$ Tregs was significantly decreased in patients with active pediatric lupus compared with patients with inactive lupus and controls and was inversely correlated with disease activity and serum anti-dsDNA levels. ${ }^{81}$ Furthermore, an elevated surface expression of GITR in $\mathrm{CD} 4{ }^{+} \mathrm{CD} 25^{+} \mathrm{T}$-cells, elevated mRNA expression of CTLA-4 in $\mathrm{CD}^{+}{ }^{+} \mathrm{T}$-cells, and higher amounts of mRNA expression for FOXP3 in $\mathrm{CD}^{+}$cells in patients with active lupus disease compared with patients with inactive disease and control were noted, indicating that a defective Treg population in pediatric lupus occurs and implying a role for FOXP3, CTLA-4, GITR, and CD4 ${ }^{+}$ Tregs in the pathogenesis of lupus. These results are supported by the observation that a significant decrease in the suppressive function of $\mathrm{CD} 4^{+} \mathrm{CD} 25^{+}$Tregs from peripheral blood of patients with active lupus occurs when compared with normal donors and patients with inactive lupus. ${ }^{82}$
$\mathrm{CD} 4{ }^{+} \mathrm{CD} 25^{+}$Tregs isolated from patients with active lupus expressed reduced levels of FoxP3 mRNA and protein and poorly suppressed the proliferation and cytokine secretion of $\mathrm{CD}^{+}$effector T-cells in vitro. On the other hand, the expression of FoxP3 mRNA and protein and in vitro suppression of the proliferation of $\mathrm{CD}^{+}{ }^{+}$effector T-cells by Tregs isolated from inactive lupus patients were comparable with that of normal individuals. In vitro activation of $\mathrm{CD} 4{ }^{+} \mathrm{CD} 25^{+}$Tregs from patients with active lupus increased FoxP3 mRNA and protein expression and restored their suppressive function, demonstrating that the defect in $\mathrm{CD} 4{ }^{+} \mathrm{CD} 25^{+}$Treg function in patients with active lupus is reversible. It was also noted that in newly admitted patients with the first manifestations of the disease and those treated with cytostatics and steroids, the coexpression of FoxP3 on CD $4{ }^{+} \mathrm{CD} 25 \mathrm{~T}$-cells was significantly reduced in both groups regardless of the therapy. ${ }^{83}$ The ability of Tregs to suppress proliferation of autologous $\mathrm{CD}^{+}$and $\mathrm{CD} 4^{+} \mathrm{T}$-cells was significantly reduced in both groups of patients compared with healthy donors, though impaired production of Tregs in lupus patients could be partly restored by conventional treatments. These results imply that measurement of FoxP3 on $\mathrm{CD} 4{ }^{+} \mathrm{CD} 25 \mathrm{~T}$-cells and Tregs in lupus could form a marker of response to therapy and prognostic indicator and can be a new therapeutic strategy in lupus. It may be noted here that these results are not without controversy. ${ }^{84}$ Despite these controversies, it is likely that analysis of peripheral blood FOXP $3^{+}$T-cells may be useful for the evaluation of lupus disease activity.

It is reasonable to suggest that inflammatory responses of the immune system against several autoantigens seen in lupus are due to the continuous presence of autoantibodies and leaked autoantigens, eg, from not properly cleared dying and dead cells. Various soluble molecules and biophysical properties of the surface of apoptotic cells play significant roles in the appropriate recognition and further processing of dying and dead cells. It is important that an efficient clearance of dying cells in early and late phases of cell death is important to prevent activation of the immune response against self-antigens. The exposure of phosphatidylserine (PS) on the surface of apoptosing cells is recognized by several receptors and adaptor molecules for their clearance. Dying cells have cell membranes with high lateral mobility of PS, which contributes to their efficient clearance. Complement binding is an early event in necrosis and a late event in apoptosis. Complement, C-reactive protein (CRP) and serum DNase I act as backup molecules in the clearance process. Inappropriate accumulation of secondary necrotic cells and cellular debris in the germinal centers of secondary 
lymph organs can lead to autoimmunity, and thus clearance defects are major players in the development of autoimmune diseases such as lupus. ${ }^{85,86}$

It is also important to note that high-dose cyclosporine (50 $\mathrm{mg} / \mathrm{kg}$ cyclosporine) to pretransplant donor-specific blood transfusion abrogated Tregs generation, whereas a lower dose $(10 \mathrm{mg} / \mathrm{kg})$ of cyclosporine promoted Tregs development either in synergy with perioperative donorspecific blood transfusion or by its own effect. ${ }^{87}$ These data suggest that, at times, a lower dose of cyclosporine is more beneficial in patients with lupus and RA aimed at inducing Tregs.

\section{UV radiation-induced skin lesions in lupus and mast cells}

The ability of UV radiation to suppress immune system is particularly interesting because understanding the molecular mechanisms of its action could pave the way to developing newer therapeutic strategies for immunological disorders. The beauty of immunosuppression induced by UV radiation lies in the fact that in contrast to conventional immunosuppression by immunosuppressive drugs, UV radiation does not compromise the immune system in a general fashion but rather in an antigen-specific fashion via induction of immunotolerance that is mostly mediated via regulatory T-cells (Treg). UV-induced Tregs express CD4 ${ }^{+}$and CD25 $5^{+}$ and release upon activation the immunosuppressive cytokine IL-10 that suppresses immune responses in a general fashion called bystander suppression. ${ }^{88}$

On the other hand, the absence of immunosuppression to UV radiation in patients with lupus is rather puzzling, given its immunosuppressive nature. UV radiation-induced worsening of skin lesions in patients with lupus suggests not only that the responses of keratinocytes to UV radiation in lupus do not generate $\mathrm{CD} 4{ }^{+} \mathrm{CD} 25^{+}$Tregs that release IL-10 to produce immunosuppression but also that in fact they may induce inflammation.

The paradoxical role of UV radiation in inducing immunosuppression in normal but worsening skin lesions in lupus can be related to the interaction of UV radiation with mast cells. ${ }^{89}$ There is evidence to suggest that mast cells play an important role in the pathogenesis of lupus, RA, and other collagen vascular diseases.$^{90}$ Recent evidence suggests that mast cells and their mediators, including LTs, play a significant role in collagen vascular diseases. ${ }^{91}$ Several studies are in agreement with the concept that mast cells may contribute to the pathogenesis of connective tissue diseases scleroderma, vasculitic syndromes, and lupus. ${ }^{92,93}$ For example, inhibition of the growth factor receptor of human mast cells, c-Kit, by the selective tyrosine kinase inhibitor imatinib mesylate induces apoptosis of synovial tissue mast cells, and preliminary findings suggest that inhibition of c-Kit could have antirheumatic activity.

Recent studies have suggested that keratinocyte apoptosis induced by ultraviolet-B radiation could be a potential source of fragmented autoantigens in lupus. The expression of Bcl-2, PCNA, p53, and Ki-67 proteins was studied by immunohistochemistry. In dermatomyositis and cutaneous lupus skin, the number of apoptotic keratinocytes was found to be significantly increased compared with normal skin. A large number of apoptotic keratinocytes expressed $\mathrm{p} 53$ protein; an increase in the number of proliferating Ki-67-positive and PCNA (proliferating cell nuclear antigen)-positive nuclei associated with exaggerated and inappropriate keratinocyte apoptosis was reported in these diseases compared with control. These results suggest that solar radiation induces DNA damage and excessive keratinocyte apoptosis in dermatomyositis and cutaneous lupus that could be responsible for the epidermal lesions observed in both diseases. ${ }^{94}$ These results, coupled with the observation that in UVB-induced and lupus skin lesions in lupus patients there could be a defect in the removal of the apoptotic cells, ${ }^{95}$ suggest that humoral factors that play a significant role in inducing macrophages to clear cell debris such as LXs, resolvins, protectins, and maresins ${ }^{96}$ may play a significant role in skin lesions in autoimmune diseases.

Based on these data, it is likely that methods designed to enhance NO generation, enhance the number of Treg cells, block proinflammatory $\mathrm{PG}$ synthesis, stabilize mast cells, and enhance the synthesis and release of anti-inflammatory lipid mediators such as LXs, resolvins, protectins, and maresins could be of benefit in lupus and other collagen vascular diseases. In this context, the role of PUFAs and their pro- and anti-inflammatory metabolites in inflammation appears to be important.

\section{Pro- and anti-inflammatory lipids and their role in lupus}

Inflammation is not a single event but a process in which cellular influx, persistence, and resolution of inflammation are controlled by several endogenous stop and go signals. It is evident from the discussion (see Metabolism of essential fatty acids) that products from AA, EPA, and DHA not only form precursors to various proinflammatory molecules such as $\mathrm{PGE}_{2}, \mathrm{PGF}_{2 \alpha}, \mathrm{TXs}$, and LTs but also give rise to LXs and ATLs, resolvins, and protectins that are anti-inflammatory 
in nature. For these pro- and anti-inflammatory compounds to form, initial activation of $\mathrm{PLA}_{2}$ that releases the precursors from the cell membrane lipid pool is essential. Thus, there are two phases of release of PUFAs: one at onset of the generation of proinflammatory PGs, TXs, and LTs and one at the time of resolution for the synthesis of antiinflammatory LXs and ATLs, resolvins, and protectins.

There are three classes of phospholipases that control the release of AA and other PUFAs: calcium-independent $\mathrm{PLA}_{2}\left(\mathrm{iPLA}_{2}\right)$, secretory $\mathrm{PLA}_{2}\left(\mathrm{sPLA}_{2}\right)$, and cytosolic $\mathrm{PLA}_{2}\left(\mathrm{cPLA}_{2}\right) \cdot{ }^{97}$ Each class of $\mathrm{PLA}_{2}$ is further divided into isoenzymes: 10 for mammalian $\operatorname{sPLA}_{2}$, at least three for cPLA $_{2}$, and two for iPLA ${ }_{2}$. During the early phase of inflammation, COX-derived PGs and lipoxygenase-derived LTs initiate exudate formation and inflammatory cell influx. ${ }^{8}$ TNF- $\alpha$ causes an immediate influx of neutrophils concomitant with $\mathrm{PGE}_{2}$ and $\mathrm{LTB}_{4}$ production, whereas during the phase of resolution of inflammation an increase in $\mathrm{LXA}_{4}$ (lipoxin $\mathrm{A}_{4}$ ), $\mathrm{PGD}_{2}$, and its product 15 deoxy $\Delta^{12-14} \mathrm{PGJ}_{2}$ formation occurs, which induces resolution of inflammation with a simultaneous decrease in $\mathrm{PGE}_{2}$ synthesis that stops neutrophil influx and enhances phagocytosis of debris. ${ }^{98,99}$ Thus, there appears to be two waves of release of AA and other PUFAs: one at the onset of inflammation that causes the synthesis and release of $\mathrm{PGE}_{2}$, and a second at resolution for the synthesis of anti-inflammatory $\mathrm{PGD}_{2}, 15$ deoxy $\Delta^{12-14} \mathrm{PGJ}_{2}$, and LXs, which is necessary for the suppression of inflammation. Thus, COX-2 enzyme has both harmful and useful actions by virtue of its ability to give rise to proinflammatory and anti-inflammatory PGs and LXs.

Increased type VI iPLA, protein was found to be the principal isoform expressed from the onset of inflammation up to $24 \mathrm{~h}$, whereas type IIa and V sPLA 2 were expressed from the beginning of $48 \mathrm{~h}$ to $72 \mathrm{~h}$. Type IV cPLA 2 was not detectable during the early phase of acute inflammation but increased progressively during resolution, peaking at $72 \mathrm{~h}$.

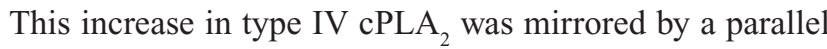
increase in COX-2 expression. ${ }^{100}$ The increase in $\mathrm{CPLA}_{2}$ and COX-2 occurred in parallel, suggesting a close enzymatic coupling between them. Thus, there is a clear-cut role for different types of PLA $\mathrm{P}_{2}$ in distinct and different phases of inflammation. Selective inhibition of $\mathrm{cPLA}_{2}$ resulted in the reduction of proinflammatory molecules $\mathrm{PGE}_{2}, \mathrm{LTB}_{4}$, IL-1 $\beta$, and PAF. Furthermore, inhibition of types IIa and V sPLA $_{2}$ not only decreased PAF and LXA 4 but also resulted in a reduction in $\mathrm{CPLA}_{2}$ and $\mathrm{COX}-2$ activities. These results suggest that $\mathrm{SPLA}_{2}$-derived PAF and $\mathrm{LXA}_{4}$ induce COX-2 and type IV $\mathrm{cPLA}_{2}$. IL-1 $\beta$ induced $\mathrm{cPLA}_{2}$ expression. This suggests that one of the functions of IL-1 is not only to induce inflammation but also to induce $\mathrm{cPLA}_{2}$ expression to initiate resolution of inflammation. ${ }^{101,102}$ Synthetic glucocorticoid dexamethasone inhibited both $\mathrm{CPLA}_{2}$ and $\mathrm{sLA}_{2}$ expression, whereas type IV $\mathrm{iPLA}_{2}$ expression is refractory to its suppressive actions. ${ }^{5,100,103}$ Activated iPLA $_{2}$ contributes to the conversion of inactive proIL- $1 \beta$ to active IL-1 $\beta$, which in turn induces $\mathrm{cPLA}_{2}$ expression that is necessary for resolution of inflammation. Both TNF- $\alpha$ and MIF might have a direct suppressive action on the synthesis of $\mathrm{LXs}, \mathrm{PGD}_{2}$, and 15 deoxy $\Delta^{12-14} \mathrm{PGJ}_{2}$ from $\mathrm{cPLA}_{2}$-induced release of $\mathrm{AA} /$ EPA/DHA. On the other hand, LXs, especially LXA ${ }_{4}$, inhibit TNF- $\alpha$-induced production of ILs; promote TNF- $\alpha$ mRNA decay, TNF- $\alpha$ secretion, and leukocyte trafficking; and thus attenuate inflammation. This close interaction among $\operatorname{PLA}_{2} \mathrm{~S}$, $\mathrm{COX}-2, \mathrm{PGD}_{2}, \mathrm{LXA}_{4}$, and PAF in the initiation, maintenance, and resolution of inflammation suggests that any imbalance in this complex interplay during the various phases of inflammation could lead to either less optimal inflammation or persistence of inflammation.

Local levels of endogenous glucocorticoids appear to play a major role in the resolution of the inflammatory process. Corticosterone is released very early in the course of inflammation by stimulating the hypothalamic-pituitaryadrenal axis by TNF- $\alpha$, IL- $1 \beta$, and IL- 6 , an event that is critical to the resolution of inflammation. ${ }^{104}$ It is known that iPLA $_{2}$ is resistant to the inhibitory actions of dexamethasone, whereas both $\mathrm{cPLA}_{2}$ and $\mathrm{sPLA}_{2}$ are inhibited. During the normal course of an inflammatory process, the local concentrations of endogenous corticosterone are high, whereas at the time of resolution they are low so that both $\mathrm{cPLA}_{2}$ and $\mathrm{sPLA}_{2}$ can be expressed to augment the production of LXs, $\mathrm{PGD}_{2}$, and $15 \mathrm{deoxy} \Delta^{12-14} \mathrm{PGJ}_{2}$ to induce resolution of inflammation. Chronic use of corticosteroids would suppress $\mathrm{SPLA}_{2}$ and $\mathrm{cPLA}_{2}$ expression that is essential for the production of $\mathrm{LXs}, \mathrm{PGD}_{2}$, and 15 deoxy $\Delta^{12-14} \mathrm{PGJ}_{2}$ to resolve inflammation, which explains why long-term use of steroids leads to nonhealing of inflammatory lesions and a flare-up of the inflammatory process when steroids are stopped.

It is interesting that $\mathrm{PLA}_{2}$ enhances the conversion of pro-IL-1 $\beta$ to IL-1 $\beta$ by IL-converting enzyme. ${ }^{105}$ In contrast, high concentrations of $\mathrm{cPLA}_{2}$ suppress the conversion of pro-IL-1 $\beta$ to IL-1 $\beta$. The formation of both $\mathrm{LXA}_{4}$ and PAF is maximal at the initiation of resolution of inflammation. Furthermore, both $\mathrm{LXA}_{4}$ and PAF have the ability to upregulate COX-2 and cPLA 2 expression, and COX-2 brings about the synthesis of $\mathrm{PGD}_{2}$ and 15 deoxy $\Delta^{12-14} \mathrm{PGJ}_{2}$, which have 
anti-inflammatory actions. These results suggest that under normal physiological conditions, several lipid molecules act in a coordinated manner to resolve inflammation.

These findings suggest that both in RA and lupus, the flares and remissions are somewhat similar to onset and resolution of acute inflammatory process described above, in as much as the cell profile and mediators that initiate the response are similar. It is evident from the preceding discussion that COX-2 has an important role in resolving inflammation, ${ }^{19}$ and hence the failure of NSAIDs to halt the progression of disease(s) could be due to the inhibition of COX-2.

\section{Glucocorticoids and lipid mediators in inflammation}

Corticosteroids are widely used in the treatment of various inflammatory conditions. Although corticosteroids are effective anti-inflammatory compounds, they also have significant side effects. Glucocorticoids bring about their anti-inflammatory actions by 1) the induction and activation of annexin 1 (also called lipocortin-1), ${ }^{106}$ ) the induction of mitogen-activated protein kinase (MAPK) phosphatase $1,{ }^{107}$ and 3) the inhibition of COX-2 ${ }^{108}$ and iNOS. ${ }^{109,110}$ Annexin-1 or lipocortin-1 physically interacts with and inhibits $\mathrm{CPLA}_{2 \alpha}$ so that $\mathrm{AA}$ is not released in adequate amounts to form precursors to various proinflammatory eicosanoids. Increased expression of $\mathrm{CPLA}_{2}$ is necessary to give rise to anti-inflammatory molecules $\mathrm{PGD}_{2}$ and 15 deoxy $\Delta^{12-14} \mathrm{PGJ}_{2}$, and LXs. Thus, the timing and quality and quantity of expression (perhaps a pulsatile expression) of $\mathrm{cPLA}_{2}$ and the local concentrations of glucocorticoids could be important factors that determine the progression and/or resolution of inflammation. Glucocorticoids also inhibit the production of proinflammatory cytokines such as IL-1, IL-6, TNF- $\alpha$, and MIF. ${ }^{11-113}$ It is known that eNO activates constitutive COX-1, resulting in optimal release of $\mathrm{PGE}_{2}$, whereas iNO activates COX-2, resulting in markedly increased release of $\mathrm{PGE}_{2}$ and thereby inflammation. ${ }^{114}$ This implies that constitutive production of $\mathrm{NO}$ and $\mathrm{PGE}_{2}$ is antiinflammatory in nature, whereas inducible production of $\mathrm{NO}$ and $\mathrm{PGE}_{2}$ is proinflammatory, simply because the quantities of $\mathrm{NO}$ and $\mathrm{PGE}_{2}$ are extremely high in the latter instance. Low concentrations of glucocorticoids enhance MIF synthesis, which in turn overrides glucocorticoid-mediated inhibition of secretion of other proinflammatory cytokines. MIF induces the production of TNF- $\alpha$ and vice versa. Thus, there is a close interaction among glucocorticoids, MIF, TNF- $\alpha$, NO, and eicosanoids (see Figure 9).

Glucocorticoids accelerated the catabolism of $\mathrm{LTC}_{4}$ (leukotriene $\mathrm{C}_{4}$ ), a proinflammatory molecule; ${ }^{115}$ reduced
$\mathrm{PGD}_{2}, 15$-HETE, $\mathrm{LTB}_{4}$, and $\mathrm{TXB}_{2}$; and enhanced 5-HETE and $\mathrm{LTE}_{4}$ (a less proinflammatory metabolite of $\left.\mathrm{LTC}_{4}\right)^{116}$ to dampen the inflammatory process. In addition, 15-HPETE and LXs, anti-inflammatory eicosanoids, cause a significant increase in the rate of TNF degradation. ${ }^{117}$ On the other hand, $\mathrm{LXA}_{4}$ not only inhibited the secretion of TNF- $\alpha^{118}$ but also prevented TNF- $\alpha$-induced production of IL-1 $\beta$, IL- 6 , cyclin E expression, and NF- $\kappa \mathrm{B}$ activation. ${ }^{119}$ Thus, glucocorticoids and LXs have similar actions on inflammation; both are anti-inflammatory, but their mechanisms of action seem to be different. It is relevant to note that both TNF- $\alpha$ and glucocorticoids have opposite actions on $\mathrm{PLA}_{2}$ : the former stimulates ${ }^{120}$ while the latter inhibits. ${ }^{110}$ Thus, a close interaction exists among proinflammatory cytokines and lipid mediators of inflammatory and anti-inflammatory process and tissue repair (see Figure 10).

Because the amount and type of PUFA(s) released in response to inflammatory stimuli depend on the cell membrane phospholipid fatty acid content, it is reasonable to propose that dietary content PUFAs could be one factor that determines the degree of inflammation. Increased dietary intake of GLA, DGLA, and EPA/DHA substantially decreases inflammatory response ${ }^{121-126}$ as a result of decreased formation of proinflammatory eicosanoids and cytokines, and increases the production of beneficial eicosanoids such as $\mathrm{PGE}_{1}, \mathrm{PGI}_{2}, \mathrm{PGI}_{3}$, HPETEs, and eNO. ${ }^{19,127-132}$ It was noted that human embryonic kidney cells, in the presence of exogenous PUFAs (fatty acids that were used in this study were AA, LA, and oleic acid), on exposure to IL-1, preferentially released AA due to the activation of sLA $_{2}$-IIA, type IV $\mathrm{cPLA}_{2}$, and type VI iPLA ${ }_{2}$. The degree of activation of these $\mathrm{PLA}_{2}$ was as follows: sPLA $_{2}$-IIA $>$ type IV $\mathrm{cPLA}_{2}>$ type VI iPLA ${ }_{2}$, indicating that exogenous PUFAs preferentially activate type IIA sPLA $\mathrm{A}_{2}$-mediated AA release from IL-1stimulated cells. The order of release was AA $>$ LA $>$ oleic acid. ${ }^{133}$ This is interesting because it is evident from the preceding discussion that activation of $\mathrm{CPLA}_{2}$ and $\mathrm{SPLA}_{2}$ would lead to the formation of anti-inflammatory LXs, $\mathrm{PGD}_{2}$, and $15 \mathrm{deoxy} \Delta^{12-14} \mathrm{PGJ}_{2}$, lending support to the hypothesis that lipid composition of the cell membrane can potentially modulate response to inflammation.

It is also reasonable to suggest that failure to generate adequate amounts of LXs and resolvins could lead to persistence of inflammation as seen in RA, lupus, glomerulonephritis, and other conditions that could be due to continued synthesis and secretion of inflammatory cytokines IL-1, IL-2, IL-6, IL-8, TNF- $\alpha$, and MIF. On the other hand, IFN- $\gamma$ and IL-13 could trigger production of LXs and resolvins such that resolution of 


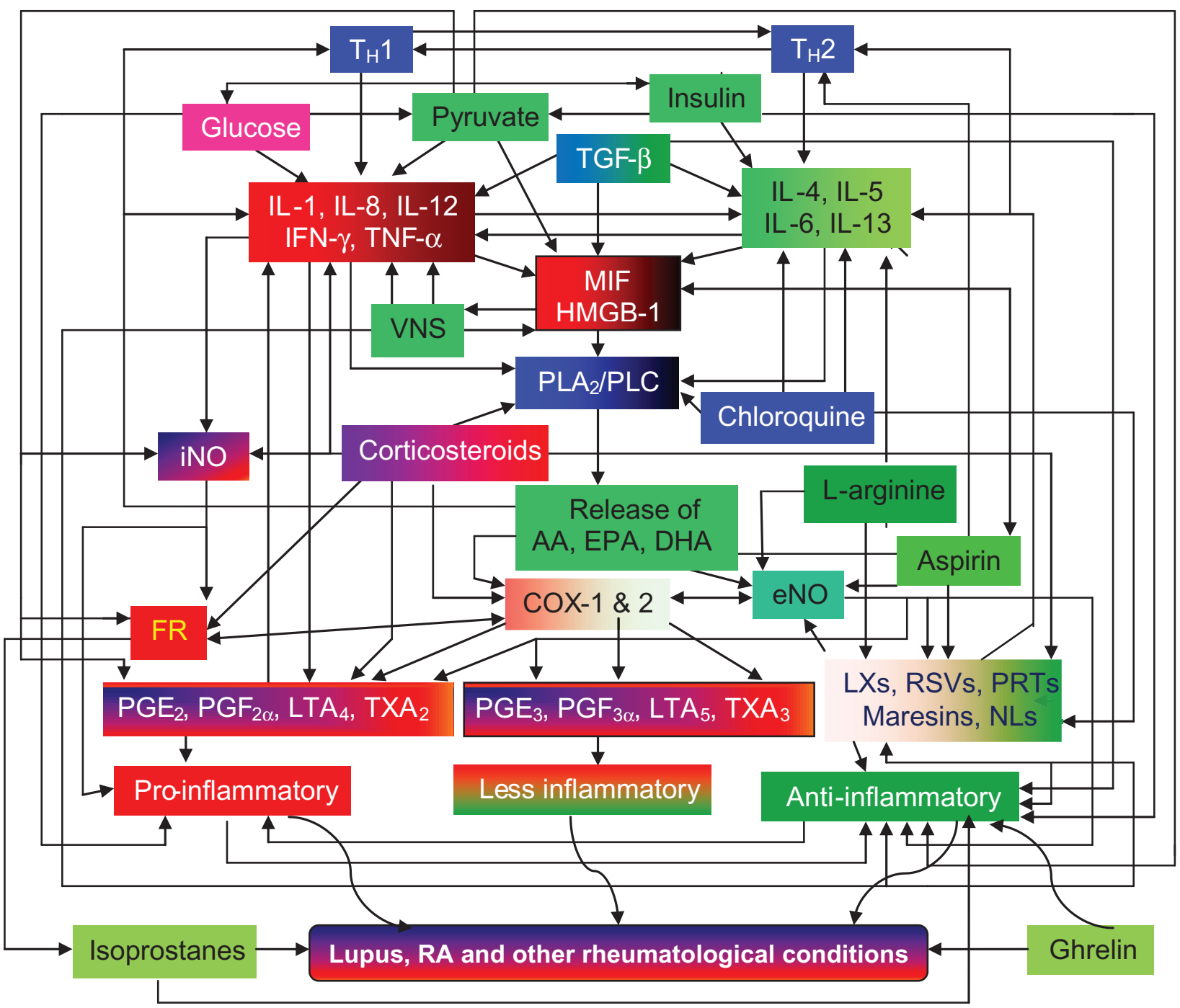

Figure 9 Scheme showing possible interaction between PUFAs (AA, EPA, and DHA), their products such as PGs, LTs, TXs, LXs, resolvins, protectins, and maresins, and $T_{H} I$ and $T_{H} 2$ and their respective cytokines. PUFAs have direct actions on $T_{H} I$ and $T_{H} 2$ responses and cytokines by themselves without being converted to their products. Ghrelin, isoprostanes (formed due to the action of free radicals on PUFAs), insulin, and pyruvate also exhibit anti-inflammatory actions. For further details see text.

inflammation is initiated. When this delicate balance between pro- and anti-inflammatory cytokines and PGs and LXs and resolvins is dysregulated, it will lead to persistence of inflammation (see Figure 10). It is possible that the balance (or ratio) between the concentrations of AA, EPA, and DHA in the cell membrane could be one factor that determines the amount of LXs, resolvins, $\mathrm{PGD}_{2}$, and 15 deoxy $\Delta^{12-14} \mathrm{PGJ}_{2}$ formed.

\section{Nitric oxide, lipid peroxides, and antioxidant status in lupus}

Serum nitrite levels were reported to be significantly elevated in patients with lupus (mean $\pm \mathrm{SEM}=37 \pm 6 \mu \mathrm{M} / \mathrm{L}$ ) compared with controls $(15 \pm \mu \mathrm{M} / \mathrm{L} ; P<0.01)$, and were elevated in patients with active lupus compared with those with inactive disease ( $46 \pm 7$ versus $30 \pm 7 \mu \mathrm{M} / \mathrm{L} ; P<0.01$ ), and serum nitrite levels correlated with disease activity and with levels of antibodies to dsDNA. Endothelial cell expression of iNOS in lupus patients was significantly greater compared with controls, and higher in patients with active disease compared with those with inactive lupus. Even keratinocyte expression of iNOS was significantly elevated in lupus compared with controls, whereas eNOS activity was similar in patients with active lupus and inactive lupus and normal controls in either the vascular endothelium or the keratinocytes. ${ }^{134}$ These and other results suggest that iNO production is enhanced in active lupus, including neuropsychiatric lupus, ${ }^{135-137}$ which could be responsible for vascular and cutaneous inflammation seen in these patients. Similar results have been reported in IgA nephropathy and lupus nephropathy, ${ }^{138-140}$ and the beneficial effect of the immunosuppressive drug mycophenolate mofetil 


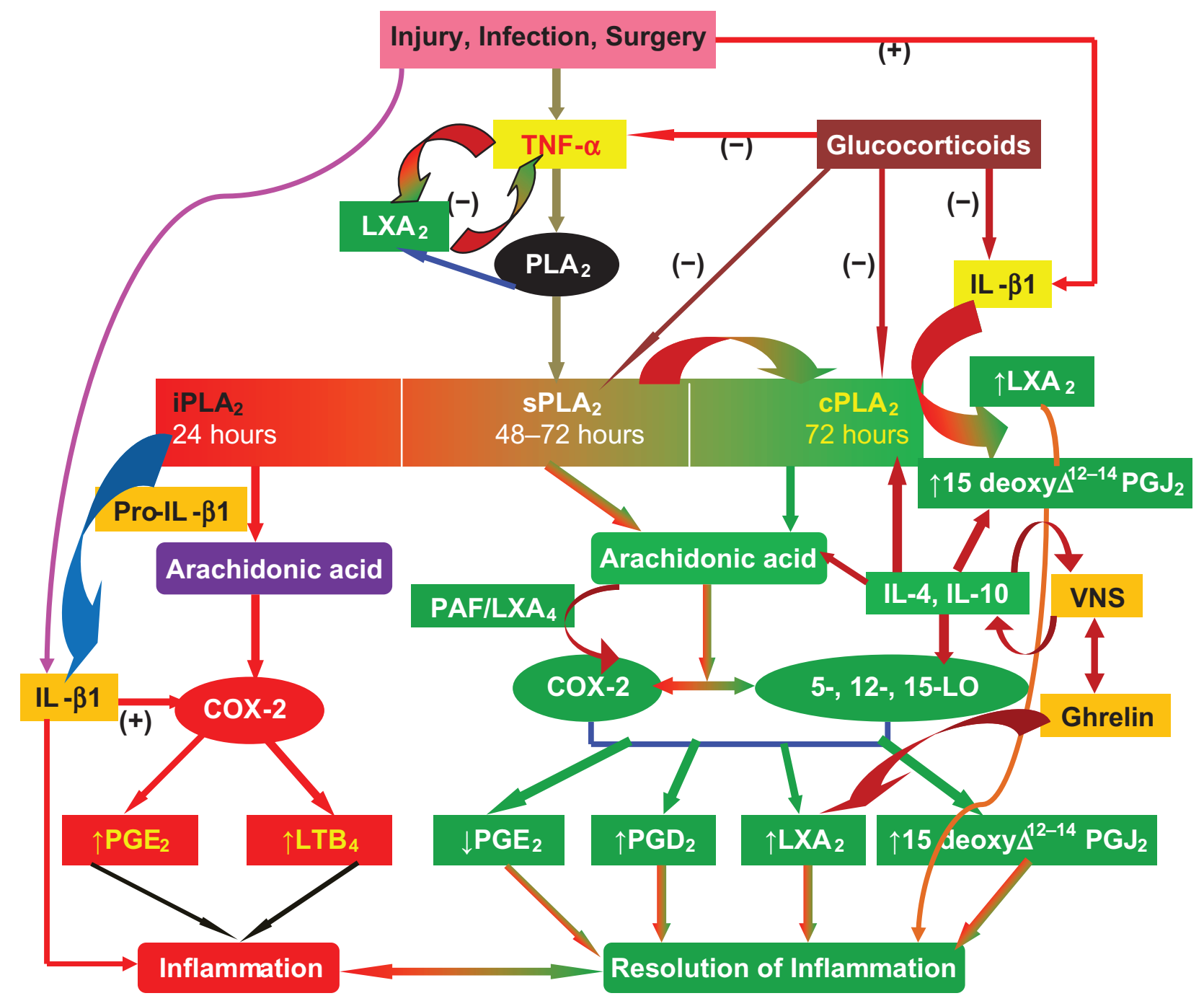

Figure 10 Scheme showing the role of prostaglandins and lipoxins in inflammation and its resolution. (-) indicates inhibition or suppression of action; (+) indicates activation or enhancement of action. For further details see text.

and anti-inflammatory compound $\mathrm{PGJ}_{2}$ has been attributed to their ability to suppress iNOS. ${ }^{139,140}$

\section{I,25-Dihydroxyvitamin $D_{3}$ suppresses autoimmunity}

The active form of vitamin D3, 1- $\alpha, 25$-dihydroxyvitamin $\mathrm{D}_{3}\left(1,25\right.$-vitamin $\left.\mathrm{D}_{3}\right)$, suppresses in vitro immunoglobulin production and inhibits IL-2 production by activated blood mononuclear cells (PBM) by specifically targeting TH lymphocytes. ${ }^{141}$ In addition, 1,25-vitamin $\mathrm{D}_{3}$ not only inhibited IL-12-generated IFN- $\gamma$ production but also suppressed IL-4 and IL-13 expression induced by IL-4. ${ }^{142}$ It also prevented partly reversed experimental autoimmune uveitis (EAU) disease by suppressing immunological responses by directly suppressing IL-17 induction in purified naive CD4(+) T-cells. ${ }^{143}$ Thus, 1,25-dihydroxyvitamin $\mathrm{D}_{3}$ appears to sup- press autoimmunity by inhibiting the Th- 17 response. This evidence suggests that 1,25-dihydroxyvitamin $\mathrm{D}_{3}$ may be useful in suppressing disease activity in patients with lupus, RA, and other rheumatological conditions. ${ }^{52}$

\section{ADMA in rheumatological conditions}

Plasma eNO levels are low in patients with lupus and RA, ${ }^{52,60,61}$ which could trigger vasospasm and cause Raynaud's phenomenon seen in rheumatological conditions. These low NO levels could be due to 1) substrate deficiency, 2) low activity of the eNOS enzyme, and 3) rapid inactivation of eNO.

Arginase and NO synthase (NOS) compete for the same substrate, 1-arginine, and the reciprocal regulation of arginase and NOS in 1-arginine-metabolizing pathways is known. Both serum arginase activity and protein levels 
were significantly higher in patients with RA compared with healthy controls. A significant correlation between the serum concentrations of arginase protein and rheumatoid factor was also noted in RA patients, suggesting that increased arginase production may be responsible for low 1-arginine levels and eNO formation. ${ }^{144}$

Asymmetric dimethylarginine (ADMA), an endogenous NO synthesis inhibitor, is an independent risk factor for endothelial dysfunction and cardiovascular disease. Mean plasma ADMA levels were significantly higher in patients with lupus with a history of cardiovascular episodes than in patients without such a history, and high SLEDAI (SLE disease activity index) score, high titer of anti-dsDNA antibodies, and low serum HDL were significantly associated with high plasma ADMA levels. These results suggest that patients with lupus are at high risk of developing cardiovascular diseases due to high plasma ADMA levels. ${ }^{145}$ In addition, it was reported that TNF- $\alpha$ levels and other indices that reflect endothelial damage, such as SVCAM-1, were found to be elevated in lupus and other rheumatological conditions. ${ }^{146,147}$ Further support to the role of NO in rheumatological conditions is derived from previous studies where it was observed that drug-resistant Raynaud's phenomenon in lupus responds to oral 1 -arginine therapy. ${ }^{148}$ That could be attributed to an increase in the generation of NO. These results are supported by the work of Fries et al, ${ }^{149}$ who showed that sildenafil, the NO donor, is of benefit in the management of Raynaud's phenomenon.

Increased production of IL-1, IL-6, TNF- $\alpha$, IFN- $\gamma$, MIF, and HMGB-1 attracts neutrophils, macrophages, and T-cells to initiate and perpetuate the inflammatory process by increasing the production of free radicals, eicosanoids, and cytokines in an autocrine fashion. ${ }^{1}$ IL-1 increases the production of endothelin-1 in cultured endothelial cells, ${ }^{150}$ and this contributes to vasospasm seen in lupus. Endothelial cells also produce $\mathrm{PGI}_{2}$ and $\mathrm{NO}$, which are potent vasodilators and platelet antiaggregators and natural antagonists of endothelin-1. Hence, enhancing the production of NO and/ or decreasing endothelin-1 and suppressing the production of proinflammatory molecules and enhancing the synthesis of anti-inflammatory molecules could be of significant benefit in lupus and other rheumatological conditions.

In this context, it is interesting to note that recent studies have led to the identification of several newer methods of suppressing inappropriate generation of free radicals and proinflammatory cytokines, enhancing resolution of inflammation, and restoring immune balance and organ dysfunction to normal. Some of these strategies include immunosuppressive drugs such as FK-506, B-cell-targeted therapies, complement-component-targeted therapies, use of monoclonal antibodies against IFN- $\alpha$, glucose-insulin infusion, administration of EP, lipid-enriched albumin, vagal nerve stimulation, and use of endogenous anti-inflammatory lipids such as LXs, resolvins, protectins, or their synthetic analogs along with their precursor PUFAs in combination with aspirin. These newer methods could be adopted in addition to the existing therapeutic modalities. A brief summary of these proposed newer therapeutic strategies is outlined below.

\section{FK-506}

Tacrolimus (also FK-506 or Fujimycin) is an immunosuppressive drug that is mainly used after allogeneic organ transplant to reduce the activity of the immune system, thereby lowering the risk of organ rejection. It reduces IL-2 production by T-cells. It is also used in a topical preparation in the treatment of severe atopic dermatitis (eczema), severe refractory uveitis after bone marrow transplantation, and the skin condition vitiligo. It is a 23 -membered macrolide lactone derived from the bacteria Streptomyces tsukubaensis.

In T-cells, activation of the T-cell receptor increases intracellular calcium, which acts via calmodulin to activate calcineurin. That dephosphorylates the transcription factor NF-AT (nuclear factor of activated T-cells), which moves to the nucleus of the T-cell and increases the activity of gene coding for IL-2 and related cytokines. Tacrolimus prevents the dephosphorylation of NF-AT. Tacrolimus reduces peptidylprolyl isomerase activity by binding to the immunophilin FKBP12 (FK-506 binding protein), forming FKBP12-FK-506 complex, which interacts with and inhibits calcineurin, thus inhibiting both T-lymphocyte signal transduction and IL-2 transcription. ${ }^{151}$ Although this activity is similar to cyclosporin, studies have shown that the incidence of acute rejection is reduced by tacrolimus use over cyclosporin. Although short-term immunosuppression concerning patient and graft survival is found to be similar between the two drugs, tacrolimus results in a more favorable lipid profile. This may have important long-term implications, given the prognostic influence of rejection on graft survival.

In a study involving patients with end-stage renal disease secondary to lupus who received kidney transplantation, the actuarial patient and graft survivals at 5 years were noted to be $100 \%$ and $93 \%$, respectively, in those who received calcineurin-based immunosuppression (cyclosporine or tacrolimus). 
Recurrence of clinical or serological disease of lupus was never detected. This favorable response observed in these patients of lupus suggested that tacrolimus or cyclosporine at low doses is effective in preventing lupus reactivation. ${ }^{152}$ Several recent studies have confirmed the beneficial actions of tacrolimus or FK-506, especially in the management of lupus nephritis. ${ }^{153,154}$

\section{B-cell-targeted therapies for lupus}

Rituximab is a chimeric monoclonal antibody against the protein $\mathrm{CD} 20$, which is primarily found on the surface of B-cells. It can therefore destroy B-cells. Rituximab is used in the treatment of many lymphomas and leukemias, to suppress transplant rejection and autoimmune disorders.

There are increasing data from open-label studies to suggest that B-cell depletion using rituximab is useful in the treatment of lupus. ${ }^{155}$ However, larger double-blind clinical trials to confirm this belief are awaited. Rituximab has been shown to be an effective RA treatment in three randomized controlled trials and is now licensed for use in refractory rheumatoid disease. ${ }^{156}$ In the United States, it has been approved for use in combination with methotrexate for reducing signs and symptoms in adult patients with moderately to severely active RA who have had an inadequate response to one or more anti-TNF- $\alpha$ therapies. There is some evidence for efficacy, but not necessarily safety, and rituximab is widely used off-label to treat lupus. There are significant concerns about progressive multifocal leukoencephalopathy (PML) infection in lupus.

Another B-cell-targeted therapeutic approach is to block costimulatory interactions between T- and B-cells. Blockade of the CD40-CD40 ligand pathway has met with variable clinical benefit and unfortunate thromboembolic complications, although inhibition of the B7 pathway with cytotoxic T-lymphocyte antigen-4Ig is currently under early investigation in lupus clinical trials. In a phase II, doubleblind, placebo-controlled trial of the safety and efficacy of three different doses administered in addition to standard therapy, belimumab, a fully human monoclonal antibody that specifically binds to and neutralizes the B-lymphocyte stimulator (BLyS or B-cell-activating factor (BAFF)), was well tolerated but reportedly did not meet primary efficacy endpoints. ${ }^{157}$ Blockade of BAFF is still viewed as a promising therapeutic approach, and additional agents that interfere with the BAFF pathway are under study. Overall, therapies targeting B-cells appear to be promising in the treatment of lupus, but more convincing data need to be obtained before their approval for use in the clinic. ${ }^{158}$

\section{Complement-component-targeted therapy for lupus}

Two members of the pentraxin family of proteins, CRP and serum amyloid P component (SAP), bind to chromatin and are involved in the solubilization and clearance of nuclear material. It is known that CRP binding to chromatin is mediated by histones. SAP differs from CRP in being able to bind to DNA. CRP is an activator of the classical complement pathway, and complement-dependent cleavage of chromatin in the presence of CRP and serum is known to occur. Oligomers of SAP have been found to bind to $\mathrm{C} 1 \mathrm{q}$ and consume total $\mathrm{C}$ and $\mathrm{C} 4$, indicating that $\mathrm{SAP}$ can activate complement as well. SAP binding to histones $\mathrm{H} 1$ and $\mathrm{H} 2 \mathrm{~A}$ was observed as well as SAP binding to chromatin. In contrast to CRP, SAP binding to chromatin did not require H1. SAP partially inhibited CRP binding to chromatin and to H1. Binding of either CRP or SAP to H2A activated complement in SAP-depleted serum, leading to the deposition of $\mathrm{C} 4$ and $\mathrm{C} 3$. Complement activation required $\mathrm{C} 1 \mathrm{q}$ and produced $\mathrm{C} 4 \mathrm{~d}$, indicating that it occurred through the classical pathway and suggesting that CRP and SAP share histone as well as chromatin binding and that both pentraxins can activate the classical $C$ pathway after ligand binding. ${ }^{159}$

SAP shows specific calcium-dependent binding to DNA and chromatin in physiological conditions. The avid binding of SAP displaces H1-type histones and thereby solubilizes native long chromatin, which is otherwise profoundly insoluble at the physiological ionic strength of extracellular fluids. SAP binds in vivo to apoptotic cells, the surface blebs of which bear chromatin fragments, and to nuclear debris released by necrosis. SAP may therefore participate in handling of chromatin exposed by cell death. Mice with targeted deletion of the SAP gene spontaneously develop antinuclear autoimmunity and severe glomerulonephritis, a phenotype resembling human lupus. The $\mathrm{SAP}^{-/}$mice also have enhanced anti-DNA responses to immunization with extrinsic chromatin, and degradation of long chromatin is retarded in the presence of SAP both in vitro and in vivo, suggesting that SAP has an important physiological role of inhibiting the formation of pathogenic autoantibodies against chromatin and DNA, probably by binding to chromatin and regulating its degradation. ${ }^{160,161}$ This is supported by the observation that the measurement of antichromatin, but not anti-C1q, antibodies in patients with lupus increases diagnostic sensitivity and specificity for lupus and assists in treatment decisions in anti-dsDNA-negative patients. ${ }^{162}$ However, the role of SAP in the development of autoimmune diseases has been disputed. ${ }^{163}$ 
Nevertheless, it is useful to measure serum levels of $\mathrm{CH} 50, \mathrm{C} 3$, and $\mathrm{C} 4$ in patients with immune-mediated diseases. Recent studies have demonstrated that the defect in the clearance of immune complexes and apoptotic cells is associated with autoimmune disease. Mice deficient in $\mathrm{Clq}$ show a lupus-like phenotype with the appearance of antinuclear antibodies and glomerulonephritis due to a defect in the clearance of immune complexes and apoptotic cells. This at least explains the paradox that, in humans, deficiency in an early complement component is a major risk factor for lupus. Because the complement system is a central mediator of inflammation, it is considered as a promising therapeutic target. Anti-C5 monoclonal antibody blocks the final stage of complement activation. Pexelizumab is a single-chain, shortacting, anti-C5 antibody and is used for reperfusion after myocardial infarction, or for coronary artery bypass graft surgery with cardiopulmonary bypass, whereas eculizumab is a long-acting, anti-C5 antibody used for paroxysmal nocturnal hemoglobinuria, rheumatoid arthritis, and membranous glomerulonephritis with promising results. ${ }^{164,165}$

\section{Monoclonal antibodies against IFN- $\alpha$}

The immunoregulator human $\gamma$-interferon (IFN- $\gamma$ ) suppressed the spontaneous in vitro synthesis and secretion of antiDNA antibodies by peripheral blood mononuclear cells of patients with lupus. Comparable levels of suppression were observed with both natural human IFN- $\gamma$ and recombinant derived human IFN- $\gamma$, and the inhibitory effects of human IFN- $\gamma$ could be completely neutralized by a monoclonal antibody directed against it. Human IFN- $\gamma$ also inhibited the antigen-induced production of anti-DNA synthesis by peripheral blood mononuclear cells of patients with lupus, probably by acting directly on the B-cell. Furthermore, human IFN- $\gamma$ suppressed the spontaneous production of $\operatorname{IgG}$ and IgM by peripheral blood mononuclear cells of patients with lupus. ${ }^{166}$ These findings support the possibility that immunoglobulin production in lupus can be regulated and that human IFN- $\gamma$ could be useful in the treatment of lupus and other immune complex diseases. However, this optimism was short-lived. ${ }^{167}$

Subsequent studies showed that patients with lupus have an increased expression of type I IFN-regulated genes because of a continuous production of IFN- $\alpha$. Plasmacytoid dendritic cells (pDCs) activated by immune complexes containing nucleic acids secrete type I IFN in lupus. Type I IFN causes differentiation of monocytes to myeloid-derived dendritic cell ( $\mathrm{mDC}$ ) and activation of autoreactive T- and B-cells. Therefore, it is argued that inhibition of IFN- $\alpha$ could be useful in the management of lupus. Recent data from a phase I clinical trial suggest that administration of neutralizing monoclonal antibodies against anti-IFN- $\alpha$ can ameliorate disease activity. ${ }^{168}$ However, more clinical data are necessary before the use of neutralizing monoclonal antibodies against anti-IFN- $\alpha$ comes into clinical practice.

\section{Proresolution of inflammation, repair, and wound healing induction as a therapeutic strategy for lupus and other autoimmune diseases}

It is evident from the preceding discussion that current therapeutic approaches have been directed to suppress inflammation and immune response as their major objectives in the management of lupus and other autoimmune disorders. Although these strategies have been reasonably successful, they are associated with many side effects, and induction of disease remission has not been truly successful. The current therapeutic approaches are associated with many side effects, such as susceptibility to infections, development of hypertension and diabetes mellitus (especially with corticosteroids and cyclosporine), the unpredictable nature of remission, and recurrences of the underlying disease and in the long-term development of malignancies. These unwarranted side effects suggest that more robust and reliable and, perhaps, novel therapeutic approaches are needed in the management of lupus and other autoimmune diseases. Until now, relatively little attention has been paid to the resolution and repair phase of inflammation and to exploiting these mechanisms to devise newer therapeutic approaches to lupus. The natural process of resolution of inflammation and wound healing is successfully implemented by our body to allow many patients to recover completely from inflammation induced by infections, injury, and surgery. Such a natural process of resolution and wound repair has the capability to restore tissue architecture and function to normal. Hence, I propose that newer therapeutic strategies to manage lupus and other autoimmune diseases could be based on the principles of enhancing natural process(s) of resolution of inflammation, wound healing, and repair, so that relatively few side effects are likely to occur. Such a natural process of resolution and repair could depend on a better understanding of the normal physiology of wound healing as discussed previously. Some of the endogenous molecules involved in such resolution of inflammation, wound healing, and repair are discussed below. 


\section{Glucose-insulin-potassium regimen}

A glucose-insulin-potassium (GIK) regimen is used to treat patients with a moderate degree of hyperglycemia, even in the absence of ketoacidosis, and those with diabetic ketoacidosis. Satomi et al ${ }^{169}$ showed that glucose administration and insulin injections to presensitized mice inhibited TNF production. Fraker et a $1^{170}$ reported that recombinant human TNF-cachectin-induced decrease in food intake, nitrogen balance, and body weight gain compared with saline controls in rats can be reversed by concurrent administration of insulin without causing any treatment deaths. Further, 5 days of TNFcachectin treatment induced severe interstitial pneumonitis and periportal inflammation in the liver, and an increase in wet organ weight in the heart, lungs, kidney, and spleen in the rats could be reverted to normal when insulin treatment was given concurrently. These results suggest that administration of insulin reverses the nutritional and histopathologic toxicity of sublethal doses of TNF. Ottlecz et al ${ }^{171-173}$ showed that insulin may have anti-inflammatory action against carrageenan-induced paw edema. Boichot et al ${ }^{174}$ demonstrated that luminol-dependent chemiluminescence by the mononuclear cells in the bronchoalveolar lavage (BAL) fluid and the levels of TNF- $\alpha$ in the BAL supernatant reverted to normal levels after treatment of Wistar diabetic rats with insulin, indicating that insulin regulates superoxide anion generation and TNF- $\alpha$ synthesis and release, and thus may have anti-inflammatory action. ${ }^{170-175}$ Insulin enhances the expression of the eNOS gene both in vitro and in vivo. ${ }^{176}$ Because $\mathrm{NO}$ can quench the superoxide anion, ${ }^{177}$ this may be of benefit in inflammatory conditions. Furthermore, the expression of MIF in adipocytes can be modulated by insulin and glucose. ${ }^{178} \mathrm{MIF}$ is secreted together with insulin from pancreatic $\beta$ cells and acts as an autocrine factor to stimulate insulin release. ${ }^{179}$ During the systemic inflammatory process, including RA and lupus, MIF is secreted from the pituitary gland, accompanied by an increase in glucocorticoid secretion. The increase in plasma glucose levels that occurs as a result of this glucocorticoid secretion is probably controlled by MIF by its positive effect on insulin secretion. TNF- $\alpha$ upregulates MIF secretion. ${ }^{180} \mathrm{On}$ the other hand, TNF- $\alpha$ induces insulin resistance. ${ }^{181}$ Thus, glucose homeostasis during systemic inflammatory process is regulated by glucocorticoids, TNF- $\alpha$, MIF, and insulin. In view of the feedback control among MIF, glucose, and insulin, it is likely that infusion of glucose and insulin inhibits MIF production and release similar to their inhibitory action on TNF- $\alpha .{ }^{182-184}$ In support of this postulation, we recently showed that insulin inhibited ischemia/reperfusion-induced TNF- $\alpha$ and MPO (myeloperoxidase) production through the Akt-activated and eNOS-NO-dependent pathway in cardiomyocytes. Thus, insulin has potent anti-inflammatory properties that may contribute to its cardioprotective and cytoprotective actions. That explains its prosurvival effects in the critically ill. ${ }^{185}$ In view of this, it will be interesting to use GIK regimen in the management of patients with lupus, RA, and other rheumatological conditions. Perhaps it is worthwhile to administer insulin (without inducing hypoglycemia) twice or three times daily and monitor the clinical manifestations and plasma IL-6, TNF- $\alpha$, MIF, and NO levels in these patients. For those who are critically ill with lupus and RA, it may be interesting to administer a GIK regimen in a hospital setting and monitor their response.

\section{Ethyl pyruvate}

Pyruvic acid is present in the cells and extracellular fluids as its conjugate anion, pyruvate. Pyruvic acid, being the final product of glycolysis and the starting substrate for the tricarboxylic acid (TCA) cycle, plays a crucial role in intermediary metabolism. Pyruvate is unstable in solutions, and spontaneously undergoes condensation and cyclization. EP, a derivative of pyruvic acid, in a calcium- and potassium-containing balanced salt solution (called a Ringer EP solution) is not only stable and nontoxic but a more effective anti-inflammatory molecule than pyruvate. ${ }^{186} \mathrm{EP}$ is extensively used and approved by the Food and Drug Administration (FDA) as a food additive. EP is used in a calcium-containing solution because it is a hydrophilic compound. The calcium prevents emulsion and increases the solubility. Because EP is chemically related to lactate, substituting lactate for EP can provide a therapeutic anti-inflammatory property to the Ringer's solution. EP, derived from ethanol and pyruvic acid, in a Ringer-type $\mathrm{Ca}^{2+}$ - and $\mathrm{K}^{+}$-containing balanced salt solution is not only stable but also more effective than sodium pyruvate. ${ }^{187}$

Ringer EP solution prolonged survival of rats that were in hemorrhagic shock ${ }^{186,187}$ by effectively scavenging the free radicals. ${ }^{188-190}$ In vitro studies showed that EP inhibited the release of TNF- $\alpha$ and HMGB-1 from endotoxin-stimulated murine macrophages and attenuated activation of NF- $\mathrm{\kappa B}$ signaling pathways. In an LPS-induced endotoxic shock animal model, EP improved survival by lowering circulating concentrations of nitrite/nitrate (metabolites of NO) and IL-6, which are proinflammatory molecules, and enhanced plasma levels of IL-10, an anti-inflammatory cytokine, ${ }^{191}$ suggesting that EP has significant anti-inflammatory actions.

In view of these significant anti-inflammatory actions, ${ }^{192-194}$ it is anticipated that administration of EP may be of use in 
suppressing inflammatory events in lupus, RA, and other rheumatological conditions.

\section{Lipid-enriched albumin}

Albumin, the major protein produced by hepatocytes in the liver, maintains oncostatic pressure. Albumin traps oxygen radical and quenches free radicals, inhibits copper-ion-dependent lipid peroxidation, and retards the formation of hydroxyl radicals, and thus exhibits both neuroprotective and cytoprotective actions. This beneficial action of albumin is due to its ability to mobilize DHA and possibly other PUFAs from liver and other tissue that, in turn, are converted to anti-inflammatory molecules such as protectins, LXs, and resolvins.

On administration of albumin-DHA complex containing $2.1 \pm 0.1 \mu \mathrm{M}$ DHA $/ \mathrm{mL}$ of albumin to the $2 \mathrm{~h}$ middle cerebral artery suture-occlusion animal model, high-degree neurobehavioral and histological neuroprotection was noted. ${ }^{195}$ Albumin-DHA complex facilitates DHA delivery to the brain so that significant amounts of $\mathrm{NPD}_{1}$ could be formed to prevent ischemia-reperfusion injury. DHA confers neuroprotection by opening background $\mathrm{K}^{+}$channels and inhibiting apoptosis. Administration of albumin-DHA complex increased the formation of $\mathrm{NPD}_{1}$ and infusion of $\mathrm{NPD}_{1}$; reduced infarct size; and diminished PMNL infiltration, NF- $\kappa \mathrm{B}$ activation, and proinflammatory COX-2 expression. ${ }^{21,196}$ In view of these anti-inflammatory actions, it is possible that albumin-PUFA complexes could be of significant benefit in the management of rheumatological conditions RA and lupus.

\section{Vagal nerve stimulation suppresses inflammation}

CNS regulates the production of proinflammatory cytokines, such as TNF, IL-1, HMGB-1, IL-6, and MIF, through the efferent vagus nerve. ${ }^{197-199}$ Acetylcholine, the principal vagus neurotransmitter, inhibits the production of proinflammatory cytokines through a mechanism dependent on the $\alpha 7$ nicotinic acetylcholine receptor subunit. Thus, vagus nerve stimulation (VNS) controls the production of proinflammatory cytokines. Strong expression of a $7 \mathrm{nAChR}$ in the synovium of RA and psoriatic arthritis patients was detected. ${ }^{200}$ Both peripheral macrophages and synovial fibroblasts have been shown to respond in vitro to specific a $\mathrm{nAChR}$ cholinergic stimulation with potent inhibition of proinflammatory cytokines. ${ }^{197-199}$ It is likely that fibroblasts, especially in the lining layer, may have the ability to balance inflammatory mechanisms and arthritis development through feedback cholinergic stimulation by nearby immune cells. It is possible that specific cholinergic mechanisms may also be involved in regulation of antibody production locally in the joint. This implies that new therapies directed at regulation of the cholinergic and a7nAChR-mediated mechanisms in the management of lupus and RA could be developed.

This proposal is supported by the recent observation that measurement of RR interval variability (heart rate variability, HRV) as a marker of vagus nerve tone (which reflects parasympathetic activity) in RA patients revealed that vagus nerve activity was significantly depressed in patients compared with control. ${ }^{201}$ These findings suggest that it is possible to pharmacologically target the a $7 \mathrm{nAChR}$ dependent control of cytokine release in RA patients with suppressed vagus nerve activity. As a7nAChR agonists ameliorate the clinical course of collagen-induced arthritis in animals, it may be possible to explore whether a $7 \mathrm{nAChR}$ agonists can improve clinical activity in RA patients. Furthermore, it was reported that collagen-induced arthritis in a $7 \mathrm{nAChR}^{(--)}$mice was significantly severe and showed increased synovial inflammation and joint destruction compared with the wildtype mice. Exacerbation of the arthritis was associated with elevated systemic proinflammatory cytokines and enhanced T-helper cell 1 (Th1)-cytokine and TNF- $\alpha$ production by spleen cells. These results indicate that immune cell function in a model of RA is regulated by the cholinergic system and, at least in part, mediated by the a7nAChR. ${ }^{202}$ The clinical implications of these findings are that VNS could be employed in the treatment of lupus, RA, and other autoimmune diseases.

VNS is currently in use as an adjunctive treatment for certain types of intractable epilepsy and major depression. ${ }^{203}$ VNS uses an implanted stimulator that sends electric impulses to the left vagus nerve in the neck via a lead wire implanted under the skin. VNS implantation devices consist of a titanium-encased generator about the size of a pocket watch with a lithium battery to fuel the generator, a lead wire system with electrodes, and an anchor tether to secure leads to the vagus nerve. The battery life for the pulse generator is between 1 and 16 years, depending on the settings, ie, how strong the signal being sent is, the length of time the device stimulates the nerve each time, and how frequently the device stimulates the nerve. Implantation of the VNS device is usually done as an outpatient procedure. Because the VNS device is already in use and is relatively safe, this could be tried for the management of lupus and other autoimmune diseases.

\section{Lipoxins, resolvins, protectins, or their synthetic analogs}

As discussed previously, LXs, resolvins, and protectins are potent endogenous anti-inflammatory compounds whose 
Table I Response and/or prognosis of lupus, RA, and other rheumatological conditions can be assessed biochemically by measuring the various indices mentioned below. These indices need to be measured/assessed in addition to clinical features while employing various therapeutic approaches

\begin{tabular}{|c|c|}
\hline Biochemical/immunological test & Significance/comments \\
\hline Plasma insulin & $\begin{array}{l}\text { Insulin resistance is likely in lupus and RA. Insulin has anti-inflammatory } \\
\text { actions }\end{array}$ \\
\hline $\begin{array}{l}\text { Plasma hs-CRP, IL-6, TNF- } \alpha \text {, MIF, HMGB-I, IL-I, IL-2, } \\
\text { ICAM-I, VCAM-I, PECAM, IFN- } \gamma \text {, IL-I7, IL-I8, IL-I2, PAF }\end{array}$ & Marker of inflammation and disease activity \\
\hline IL-4, IL-I0, IL-27, TGF- $\beta$ & $\begin{array}{l}\text { These are anti-inflammatory cytokines, and their increase suggests a decrease in } \\
\text { the activity of the disease and possible impending remission }\end{array}$ \\
\hline $\begin{array}{l}\text { Plasma AA, EPA, DHA, lipoxins, resolvins, protectins, } \\
\text { maresins, nitrolipids }\end{array}$ & $\begin{array}{l}\text { These are anti-inflammatory lipid molecules; their measurement prior to disease } \\
\text { and after institution of therapy may indicate remission or progression of disease. } \\
\text { Their increase suggests a decrease or resolution of inflammation }\end{array}$ \\
\hline Plasma ADMA & $\begin{array}{l}\text { Inhibits eNO, and its levels are increased in CHD, metabolic syndrome, and } \\
\text { rheumatological conditions }\end{array}$ \\
\hline Plasma pyruvate & Pyruvate is an antioxidant and suppresses IL-6, TNF- $\alpha$, and MIF production \\
\hline Plasma I, 25 vitamin $D_{3}$ & $\begin{array}{l}\text { Has immunosuppressive and anti-inflammatory properties and levels are low in } \\
\text { metabolic syndrome and rheumatological conditions }\end{array}$ \\
\hline Acetylcholinesterase and butyrylcholinesterase & $\begin{array}{l}\text { Their activity indicates the vagal tone and the amount of acetylcholine released } \\
\text { and indirectly serve as markers of inflammation as acetylcholine is an anti- } \\
\text { inflammatory molecule }\end{array}$ \\
\hline a7nAChR expression on peripheral macrophages and & a7nAChR expression may indicate the status of cholinergic anti-inflammatory \\
\hline synovial fibroblasts & pathway and could be used to assess response to therapy as prognostic marker \\
\hline Catecholamines in peripheral leukocytes & $\begin{array}{l}\text { Catecholamines have proinflammatory action and suggest their role and } \\
\text { contribution to inflammation }\end{array}$ \\
\hline
\end{tabular}

deficiency could lead to unabated inflammation. Hence, methods designed to enhance their formation, such as coadministration of aspirin with PUFAs and/or development and use of their stable synthetic analogs, may prove to be useful in various rheumatological conditions. Such an approach is urgently needed.

\section{Ghrelin}

Ghrelin is a growth hormone secretagogue produced by the gut and is expressed in the hypothalamus and other tissues as well. Ghrelin not only plays an important role in the regulation of appetite, energy balance, and glucose homeostasis but also shows antibacterial activity, suppresses proinflammatory cytokine production, and restores gut barrier function. Ghrelin inhibits proinflammatory cytokine production, mononuclear cell binding, and nuclear factor- $\kappa \mathrm{B}$ activation in human endothelial cells in vitro and endotoxin-induced cytokine production in vivo. ${ }^{204}$ Ghrelin stimulates the vagus nerve. Experimental studies revealed that vagotomy prevented ghrelin's downregulatory effect on TNF- $\alpha$ and IL-6 production, confirming that ghrelin downregulates proinflammatory cytokines in sepsis through activation of the vagus nerve. ${ }^{205}$ Ghrelin has sympathoinhibitory properties that are mediated by central ghrelin receptors involving a NPY/Y1-receptor-dependent pathway. ${ }^{206}$ Ghrelin inhibited the production of HMGB-1 by activated macrophages, ${ }^{207}$ which may explain its beneficial action in sepsis and other inflammatory conditions. ${ }^{208,209}$ These results suggest that ghrelin infusion could be of significant benefit in lupus, RA, and other autoimmune diseases not only by its direct action of the production of proinflammatory cytokines but also by its ability to stimulate vagus that has anti-inflammatory actions.

\section{Conclusion}

Lupus, RA, and other autoimmune diseases are chronic inflammatory conditions that often have acute and intermittent inflammatory episodes. More often than not, these are lifelong diseases and are associated with considerable renal, pulmonary, and cardiac complications that could lead to death. Current therapeutic approaches depend on the use of synthetic and potent anti-inflammatory and immunosuppressive drugs that are often associated with significant side effects. Some of the current drugs in use include nonsteroidal anti-inflammatory compounds, chloroquine (hydroxychloroquine), corticosteroids (oral or parenteral), D-penicillamine, sulfasalazine, methotrexate, anti-TNF antibodies (treatment with anti-TNF monoclonal antibodies, infliximab, adalimumab, and certolizumab pegol has been shown to provide substantial benefit to patients of RA, Crohn's disease, and psoriasis through reductions in both localized and systemic expression of markers associated with inflammation), 
and immunosuppressive drugs (such as cyclosporine, cyclophosphamide, and azathioprine). Although there have been significant advances in the management of autoimmune diseases by the use of these drugs, especially biologics, their actions are often unpredictable: Not all patients respond adequately to these therapeutic approaches; moreover, significant side effects might result. Hence, as suggested above, newer therapeutic approaches are needed.

It is possible that GIK, EP, lipid-enriched albumin, VNS, PUFAs and their products LXs, resolvins, protectins, and ghrelin altogether may not be able to produce adequate immunosuppression and anti-inflammatory actions that lead to amelioration of the disease process in lupus, RA, and other autoimmune diseases. It is recommended that some of these suggested approaches could be performed in combination with the currently available therapeutic drugs. For example, GIK regimen, ethylpyruvate, lipid-enriched albumin, VNS, LXs, resolvins, protectins and their synthetic analogs, and ghrelin could be tried in combination with nonsteroidal anti-inflammatory compounds, chloroquine (hydroxychloroquine), corticosteroids (oral or parenteral), D-penicillamine, sulfasalazine, methotrexate, anti-TNF antibodies, and immunosuppressive drugs (such as cyclosporine, cyclophosphamide, and azathioprine). Another option that could be investigated is the use of anti-TNF- $\alpha$ and other biologics in combination (as a complex or separately) with EP, ghrelin, PUFAs, LXs, resolvins and protectins, and insulin and be used as parenteral infusion. All these permutations and combinations need to be tried both in the animal models of various autoimmune diseases and other inflammatory conditions and in the clinic before knowing which therapeutic approach is of significant benefit to these patients. With such an approach, one can measure various plasma tissue factors, as shown in Table 1, to determine the effectiveness of the therapeutic approach employed.

\section{Acknowledgment}

Dr UN Das was in receipt of the Ramalingaswami fellowship from the Department of Biotechnology during the tenure of this study.

\section{Disclosure}

The author reports no conflicts of interest in this work.

\section{References}

1. Das UN. Clinical laboratory tools to diagnose inflammation. Adv Clin Chem. 2006;41:189-229.

2. Serhan CN. Lipoxins and aspirin-triggered 15-epi-lipoxins are the first lipid mediators of endogenous anti-inflammation and resolution. Prostaglandins Leukot Essent Fatty Acids. 2005;73(3-4):141-162.
3. Claria J, Serhan CN. Aspirin triggers previously undescribed bioactive eicosanoids by human endothelial cell-leukocyte interactions. Proc Natl Acad Sci U S A. 1995;92(21):9475-9479.

4. Das UN. COX-2 inhibitors and metabolism of essential fatty acids. Med Sci Monit. 2005;11(7):RA233-RA237.

5. Serhan CN, Hong S, GronertK, et al. Resolvins: a family of bioactive products of omega-3 fatty acid transformation circuits initiated by aspirin treatment that counter proinflammation signals. $J$ Exp Med. 2002;196:1025-1037.

6. Das UN. Can COX-2 inhibitors-induced increase in cardiovascular disease risk be modified by essential fatty acids? J Assoc Physicians India. 2005;53:623-627.

7. Chiang N, Arita M, Serhan CN. Anti-inflammatory circuitry: lipoxin, aspirin-triggered lipoxins and their receptor ALX. Prostaglandins Leukot Essent Fatty Acids. 2005;73:163-177.

8. Levy BD, Clish CB, Schmidt B, Gronert K, Serhan CN. Lipid mediator class switching during acute inflammation: signals in resolution. Nat Immunol. 2001;2(7):612-619.

9. Serhan CN, Maddox JF, Petasis NA, et al. Design of lipoxin $\mathrm{A}_{4}$ stable analogs that block transmigration and adhesion of human neutrophils. Biochemistry. 1995;34(44):14609-14615.

10. Kerr DJ, Dunn JA, Langman MJ, et al. Rofecoxib and cardiovascular adverse events in adjuvant treatment of colorectal cancer. $N$ Engl $J$ Med. 2007;357(4):360-369.

11. Xiao G, Tasi A-L, Palmer G, Boyar WC, Marshall PJ, Kulmacz RJ. Analysis of hydroperoxide-induced tyrosyl radicals and lipoxygenase activity in aspirin-treated human prostaglandin $\mathrm{H}$ synthase-2. Biochemistry. 1997;36(7):1836-1845.

12. Zordoky BN, El-Kadi AO. Effect of cytochrome P450 polymorphism on arachidonic acid metabolism and their impact on cardiovascular diseases. Pharmacol Ther. 2010;125(3):446-463.

13. Nithipatikom K, Gross GJ. Review article: epoxyeicosatrienoic acids: novel mediators of cardioprotection. J Cardiovasc Pharmacol Ther. 2010;15(2):112-119.

14. Campbell WB, Fleming I. Epoxyeicosatrienoic acids and endotheliumdependent responses. Pflugers Arch. 2010;459(6):881-895.

15. Arnold C, Konkel A, Fischer R, Schunck WH. Cytochrome P450-dependent metabolism of omega- 6 and omega-3 longchain polyunsaturated fatty acids. Pharmacol Rep. 2010;62(3): $536-547$.

16. Kroetz DL, Zeldin DC. Cytochrome P450 pathways of arachidonic acid metabolism. Curr Opin Lipidol. 2002;13(3):273-283.

17. Gao L, Yin H, Milne GL, Porter NA, Morrow JD. Formation of F-ring isoprostane-like compounds (F3-isoprostanes) in vivo from eicosapentaenoic acid. J Biol Chem. 2006;281(20):14092-14099.

18. Grimminger F, Mayser P, Papavassilis C, et al. A double-blind, randomized, placebo-controlled trial of n-3 fatty acid based lipid infusion in acute, extended guttate psoriasis. Rapid improvement of clinical manifestations and changes in neutrophil leukotriene profile. Clin Investig. 1993;71(8):634-643.

19. Serhan CN, Clish CB, Brannon J, Colgan SP, Chiang N, Gronert K. Novel functional sets of lipid-derived mediators with antiinflammatory actions generated from omega- 3 fatty acids via cyclooxygenase 2-nonsteroidal antiinflammatory drugs and transcellular processing. J Exp Med. 2000;192(8):1197-1204.

20. Serhan CN, Clish CB, Brannon J, Colgan SP, Gronert K, Chiang N. Anti-microinflammatory lipid signals generated from dietary N-3 fatty acids via cyclooxygenase- 2 and transcellular processing: a novel mechanism for NSAID and N-3 PUFA therapeutic actions. J Physiol Pharmacol. 2000;51(4 Pt 1):643-654.

21. Marcheselli VL, Hong S, Lukiw WJ, et al. Novel docosanoids inhibit brain ischemia-reperfusion-mediated leukocyte infiltration and pro-inflammatory gene expression. J Biol Chem. 2003;278(44): 43807-43817.

22. Hong S, Gronert K, Devchand PR, Moussignac RL, Serhan CN. Novel docosatrienes and 17S-resolvins generated from docosahexaenoic acid in murine brain, human blood, and glial cells. Autacoids in antiinflammation. J Biol Chem. 2003;278(17):14677-14687. 
23. Katoh T, Lakkis FG, Makita N, Badr KF. Co-regulated expression of glomerular 12/15-lipoxygenase and interleukin-4 mRNAs in rat nephrotoxic nephritis. Kidney Int. 1994;46(2):341-349.

24. Nassar GM, Badr KF. Role of leukotrienes and lipoxygenases in glomerular injury. Miner Electrolyte Metab. 1995;21(4-5):262-270.

25. Papayianni A, Serhan CN, Phillips ML, Rennke HG, Brady HR. Transcellular biosynthesis of lipoxin A4 during adhesion of platelets and neutrophils in experimental immune complex glomerulonephritis. Kidney Int. 1995;47(5):1295-1302.

26. O'Meara YM, Brady HR. Lipoxins, leukocyte recruitment and the resolution phase of acute glomerulonephritis. Kidney Int Suppl. 1997;58:S56-S61.

27. Wu SH, Liao PY, Yin PL, Zhang YM, Dong L. Elevated expressions of 15-lipoxygenase and lipoxin A4 in children with acute poststreptococcal glomerulonephritis. Am J Pathol. 2009;174(1):115-122.

28. Lattin JE, Schroder K, Su AI, et al. Expression analysis of G proteincoupled receptors in mouse macrophages. Immunome Res. 2008;4:5.

29. Milligan G, Stoddart LA, Brown AJ. G protein-coupled receptors for free fatty acids. Cell Signal. 2006;18(9):1360-1365.

30. Oh DY, Talukdar S, Bae EJ, et al. GPR120 is an omega-3 fatty acid receptor mediating potent anti-inflammatory and insulin-sensitizing effects. Cell. 2010;142(5):687-698.

31. Baugh JA, Donnelly SC. Macrophage migration inhibitory factor: a neuroendocrine modulator of chronic inflammation. $J$ Endocrinol. 2003;179(1):15-23.

32. Das UN. Can critical illness and sepsis be predicted or prognosticated? Adv Sepsis. 2006;5:52-59.

33. Gando S, Sawamura A, Hayakawa M, Hoshino H, Kubota N, Nishihira J. High macrophage migration inhibitory factor levels in disseminated intravascular coagulation patients with systemic inflammation. Inflammation. 2007;30(3-4):118-124.

34. Chuang CC, Wang ST, Chen WC, Chen CC, Hor LI, Chuang AY. Increases in serum macrophage migration inhibitory factor in patients with severe sepsis predict early mortality. Shock. 2007;27(5):503-506.

35. Hoi AY, Hickey MJ, Hall P, et al. Macrophage migration inhibitory factor deficiency attenuates macrophage recruitment, glomerulonephritis, and lethality in MRL/lpr mice. J Immunol. 2006;177(8): $5687-5696$

36. Mizue Y, Nishihira J, Miyazaki T, et al. Quantitation of macrophage migration inhibitory factor (MIF) using the one-step sandwich enzyme immunosorbent assay: elevated serum MIF concentrations in patients with autoimmune diseases and identification of MIF in erythrocytes. Int J Mol Med. 2000;5(4):397-403.

37. Das UN. Insulin in the critically ill with focus on cytokines, reactive oxygen species, HLA-DR expression. J Assoc Physicians India. 2007; 55 Suppl:56-65.

38. Bozza FA, Gomes RN, Japiassú AM, et al. Macrophage migration inhibitory factor levels correlate with fatal outcome in sepsis. Shock. 2004;22(4):309-313.

39. Das UN. Current advances in sepsis and septic shock with particular emphasis on the role of insulin. Med Sci Monit. 2003;9(8):RA181-RA192.

40. Lehmann LE, Novender U, Schroeder S, et al. Plasma levels of macrophage migration inhibitory factor are elevated in patients with severe sepsis. Intensive Care Med. 2001;27(8):1412-1415.

41. Bozza M, Satoskar AR, Lin G, et al. Targeted disruption of migration inhibitory factor gene reveals its critical role in sepsis. $J$ Exp Med. 1999;189(2):341-346.

42. Rovensky J, Svejcar J, Pekarek J, Zitnan D, Hajzok O, Cebecauer L. Correlation between the results of the migration inhibitory factor production test with DNA and the severity of the disease in the systemic lupus erythematosus patients. Z Immunitatsforsch Exp Klin Immunol. 1975;150(1):24-30.

43. Chen WY, Li GR, Fang F, et al. The expression of migration inhibitory factor in peripheral blood mononuclear cell and its correlation with disease activity in systemic lupus erythematosus. Zhonghua Nei Ke Za Zhi. 2004;43(8):572-575.
44. Ayoub S, Hickey MJ, Morand EF. Mechanisms of disease: macrophage migration inhibitory factor in SLE, RA and atherosclerosis. Nature Clin Pract Rheumatol. 2008;4:98-105.

45. Otukesh H, Chalian M, Hoseini R, et al. Urine macrophage migration inhibitory factor in pediatric systemic lupus erythematosus. Clin Rheumatol. 2007;26(12):2105-2107.

46. Foote A, Briganti EM, Kipen Y, Santos L, Leech M, Morand EF. Macrophage migration inhibitory factor in systemic lupus erythematosus. J Rheumatol. 2004;31(2):268-273.

47. Urbonaviciute V, Fürnrohr BG, Meister S, et al. Induction of inflammatory and immune responses by HMGB1-nucleosome complexes: implications for the pathogenesis of SLE. $J$ Exp Med. 2008;205(13):3007-3018

48. Yin K, Gribbin E, Wang H. Interferon-gamma inhibition attenuates lethality after cecal ligation and puncture in rats: implication of high mobility group box-1. Shock. 2005;24(4):396-401.

49. Ayer LM, Rubin RL, Dixon GH, Fritzler MJ. Antibodies to HMG proteins in patients with drug-induced autoimmunity. Arthritis Rheum. 1994;37(1):98-103.

50. Popovic K, Ek M, Espinosa A, et al. Increased expression of the novel proinflammatory cytokine high mobility group box chromosomal protein 1 in skin lesions of patients with lupus erythematosus. Arthritis Rheum. 2005;52(11):3639-3645.

51. Barkauskaite V, Ek M, Popovic K, Harris HE, Wahren-Herlenius M, Nyberg F. Translocation of the novel cytokine HMGB1 to the cytoplasm and extracellular space coincides with the peak of clinical activity in experimentally UV-induced lesions of cutaneous lupus erythematosus. Lupus. 2007;16(10):794-802.

52. Das UN. Interaction(s) between essential fatty acids, eicosanoids, cytokines, growth factors and free radicals: relevance to new therapeutic strategies in rheumatoid arthritis and other collagen vascular diseases. Prostaglandins Leukot Essent Fatty Acids. 1991;44(4):201-210.

53. Robak E, Sysa-Jeorzejewska A, Dziankowska B, Torzecka D, Chojnowski K, Robak T. Association of interferon gamma, tumor necrosis factor alpha and interleukin-6 serum levels with systemic lupus erythematosus activity. Arch Immunol Ther Exp (Warsz). 1998;46(6): 375-380.

54. Tucci M, Calvani N, Richards HB, Quatraro CQ, Silvestris F. The interplay of chemokines and dendritic cells in the pathogenesis of lupus nephritis. Ann NY Acad Sci. 2005;1051:421-432.

55. Falk RJ, Jennette JC. Anti-neutrophil cytoplasmic autoantibodies with specificity for myeloperoxidase in patients with systemic vasculitis and idiopathic necrotizing and crescentic glomerulonephritis. $N$ Engl J Med. 1988;318(25):1651-1657.

56. Shen JY, Chen SL, Wu YX, et al. Pulmonary hypertension in systemic lupus erythematosus. Rheumatol Int. 1999;18(4):147-151.

57. Willeke P, Schluter B, Schotte H, et al. Increased frequency of GM-CSF secreting PBMC in patients with active systemic lupus erythematosus can be reduced by immunoadsorption. Lupus. 2004;13(4):257-262.

58. Williams RC Jr, Harmon ME, Burlingame R, Du Clos TW. Studies of serum C-reactive protein in systemic lupus erythematosus. J Rheumatol. 2005;32(3):454-461.

59. Lindsey NJ, Henderson FI, Malia R, Milford-Ward MA, Greaves M, Hughes P. Inhibition of prostacyclin release by endothelial binding anticardiolipin antibodies in thrombosis-prone patients with systemic lupus erythematosus and the antiphospholipid syndrome. Br J Rheumatol. 1994;33(1):20-26.

60. Das UN. Beneficial action(s) of eicosapentaenoic acid/docosahexaenoic acid and nitric oxide in systemic lupus erythematosus. Med Sci Res. 1995;23:723-726.

61. Mohan IK, Das UN. Oxidant stress, anti-oxidants and essential fatty acids in systemic lupus erythematosus. Prostaglandins Leukot Essent Fatty Acids. 1997;56(3):193-198.

62. Zamora MR, O'Brien RF, Rutherford RF, Weil JV. Serum endothelin-1 concentrations and cold provocation in primary Raynaud's phenomenon. Lancet. 1990;336(8724):1144-1147. 
63. Reimann J, Diamantstein T. Interleukin-2 allows in vivo induction of anti-erythrocyte autoantibody production in nude mice associated with the injection of rat erythrocytes. Clin Exp Immunol. 1981;43(3):641-644.

64. Redini F, Galera P, Mauviel A, Loyau G, Pujol J-P. Transforming growth factor-beta stimulates collagen and glycosaminoglycan biosynthesis in cultured rabbit articular chondrocytes. FEBS Lett. 1988;234(1):172-176.

65. Falanga V, Julien JM. Observations in the potential role of transforming growth factor-beta in cutaneous fibrosis. Systematic sclerosis. Ann NY Acad Sci. 1990;593:161-171.

66. Wong CK, Ho CY, Li EK, Lam CW. Elevation of proinflammatory cytokine (IL-18, IL-17, IL-12) and Th2 cytokine (IL-4) concentrations in patients with systemic lupus erythematosus. Lupus. 2000;9(8):589-593.

67. Horwitz DA, Gray JD, Behrendsen SC, et al. Decreased production of interleukin-12 and other Th1 type cytokines in patients with recent onset systemic lupus erythematosus. Arthritis Rheum. 1998;41(5): 838-844.

68. Takahashi S, Fossati L, Iwamoto M, et al. Imbalance towards Th1 predominance is associated with acceleration of lupus-like autoimmune syndrome in MRL mice. J Clin Invest. 1996;97(7): 1597-1604.

69. Peng SL, Szabo SJ, Glimcher LH. T-bet regulates IgG class switching and pathogenic autoantibody production. Proc Natl Acad Sci USA. 2002;99(8):5545-5550.

70. Akahoshi M, Nakashima H, Tanaka Y, et al. Th1/Th2 balance of peripheral T helper cells in systemic lupus erythematosus. Arthritis Rheum. 1999;42(8):1644-1648

71. Chan RW, Tam LS, Li EK, et al. Inflammatory cytokine gene expression in the urinary sediment of patients with lupus nephritis. Arthritis Rheum. 2003;48(5):1326-1331.

72. Lighvani AA, Frucht DM, Jankovic D, et al. T-bet is rapidly induced by interferon gamma in lymphoid and myeloid cells. Proc Natl Acad Sci USA. 2001;98(26):15137-15142.

73. Lantelme E, Mantovani S, Palermo B, Campanelli R, Sallusto F, Giachino C. Kinetics of GATA-3 gene expression in early polarizing and committed human T cells. Immunology. 2001;102(2): 123-130.

74. Lee HJ, Takemoto N, Kurata H, et al. GATA-3 induces T helper cell type 2 (Th2) cytokine expression and chromatin remodeling in committed Th1 cells. J Exp Med. 2000;192(1):105-115.

75. Arbuckle MR, McClain MT, Rubertone MV, et al. Development of autoantibodies before the clinical onset of systemic lupus erythematosus N Engl J Med. 2003;349(16):1526-1533.

76. Thompson C, Powrie F. Regulatory T cells. Curr Opin Pharmacol. 2004;4(4):408-414.

77. Kammer GM, Perl A, Richardson BC, Tsokos GC. Abnormal T cell signal transduction in systemic lupus erythematosus. Arthritis Rheum 2002;46(5):1139-1154.

78. Jiang H, Chess L. An integrated view of suppressor T cell subsets in immunoregulation. J Clin Invest. 2004;114(9):1198-1208.

79. Nelson BH. IL-2, regulatory $\mathrm{T}$ cells, and tolerance. J Immunol. 2004;172(7):3983-3988.

80. Malek TR, Bayer AL. Tolerance, not immunity, crucially depends on IL-2. Nat Rev Immunol. 2004;4(9):665-674.

81. Lee JH, Wang LC, Lin YT, Yang YH, Lin DT, Chiang BL. Inverse correlation between $\mathrm{CD} 4+$ regulatory T-cell population and autoantibody levels in paediatric patients with systemic lupus erythematosus Immunology. 2006;117(2):280-286.

82. Valencia X, Yarboro C, Illei G, Lipsky PE. Deficient CD4+CD25high $\mathrm{T}$ regulatory cell function in patients with active systemic lupus erythematosus. J Immunol. 2007;178(4):2579-2588.

83. Lyssuk EY, Torgashina AV, Soloviev SK, Nassaonov EL, Bykovskaia SN Reduced number and function of CD4+CD25highFoxP3+ regulatory $\mathrm{T}$ cells in patients with systemic lupus erythematosus. Adv Exp Med Biol. 2007;601:113-119.
84. Lin SC, Chen KH, Lin CH, Kuo CC, Ling QD, Chan CH. The quantitative analysis of peripheral blood FOXP3-expressing $\mathrm{T}$ cells in systemic lupus erythematosus and rheumatoid arthritis patients. Eur J Clin Invest. 2007;37(12):987-996.

85. Gaipl US, Sheriff A, Franz S, et al. Inefficient clearance of dying cells and autoreactivity. Curr Top Microbiol Immunol. 2006;305:161-176.

86. Kruse K, Janko C, Urbonaviciute V, et al. Inefficient clearance of dying cells in patients with SLE: anti-dsDNA autoantibodies, MFG-E8, HMGB-1 and other players. Apoptosis. 2010;15(9):1098-1113.

87. Kawai M, Kitade H, Mathieu C, Waer M, Pirenne J. Inhibitory and stimulatory effects of cyclosporine A on the development of regulatory T cells in vivo. Transplantation. 2005;79(9):1073-1077.

88. Schwarz T. 25 years of UV-induced immunosuppression mediated by $\mathrm{T}$ cells-from disregarded $\mathrm{T}$ suppressor cells to highly respected regulatory T cells. Photochem Photobiol. 2008;84(1):10-18.

89. Hart PH, Townley SL, Grimbaldeston MA, Khalil Z, Finlay-Jones JJ. Mast cells, neuropeptides, histamine, and prostaglandins in UVinduced systemic immunosuppression. Methods. 2002;28(1): 79-89.

90. Zhang Y, Ramos BF, Jakschik BA. Augmentation of reverse arthus reaction by mast cells in mice. J Clin Invest. 1991;88(3):841-846.

91. Danilewicz M, Wagrowska-Danilewicz M. Quantitative analysis of interstitial mast cells in lupus and non-lupus membranous glomerulopathy. Pol J Pathol. 2001;52(4):211-217.

92. Eklund KK. Mast cells in the pathogenesis of rheumatic diseases and as potential targets for anti-rheumatic therapy. Immunol Rev. 2007;217:38-52.

93. Woolley DE, Tetlow LC. Mast cell activation and its relation to proinflammatory cytokine production in the rheumatoid lesion. Arthritis Res. 2000;2(1):65-74.

94. Pablos JL, Santiago B, Galindo M, Carreira PE, Ballestin C, GomezReino JJ. Keratinocyte apoptosis and p53 expression in cutaneous lupus and dermatomyositis. J Pathol. 1999;188(1):63-68.

95. Reefman E, de Jong MC, Kuiper H, et al. Is disturbed clearance of apoptotic keratinocytes responsible for UVB-induced inflammatory skin lesions in systemic lupus erythematosus? Arthritis Res Ther. 2006;8(6):R156.

96. Ohira T, Arita M, Omori K, Recchiuti A, van Dyke TE, Serhan CN. Resolvin E1 receptor activation signals phosphorylation and phagocytosis. J Biol Chem. 2010;285(5):3451-3461.

97. Bonventre JV. Phospholipase A2 and signal transduction. J Am Soc Nephrol. 1992;3(2):128-150.

98. Godson C, Mitchell S, Harvey K, Petasis NA, Hogg N, Brady HR. Cutting edge: lipoxins rapidly stimulate nonphlogistic phagocytosis of apoptotic neutrophils by monocyte-derived macrophages. J Immunol. 2000;164(4):1663-1667.

99. Gilroy DW, Colville-Nash PR, Willis D, Chivers J, Paul-Clark MJ, Willoughby DA. Inducible cyclooxygenase may have anti-inflammatory properties. Nat Med. 1999;5(6):698-701.

100. Gilroy DW, Newson J, Sawmynaden P, Willoughby DA, Croxtall JD. A novel role for phospholipase $\mathrm{A}_{2}$ isoforms in the checkpoint control of acute inflammation. FASEB J. 2004;18(3):489-498.

101. Cominelli F, Nast CC, Llerena R, Dinarello CA, Zipser RD Interleukin 1 suppresses inflammation in rabbit colitis. Mediation by endogenous prostaglandins. J Clin Invest. 1990;85(2):582-586.

102. Schwab JH, Anderle SK, Brown RR, Dalldorf FG, Thompson RC. Pro- and anti-inflammatory roles of interleukin-1 in recurrence of bacterial cell wall-induced arthritis in rats. Infect Immun 1991;59(12):4436-4442.

103. Croxtall JD, Choudhury Q, Tokumoto H, Flower RJ. Lipocortin-1 and the control of arachidonic acid release in cell signalling. Glucocorticoids inhibit $\mathrm{G}$ protein-dependent activation of cPLA2 activity. Biochem Pharmacol. 1995;50(4):465-474.

104. Munck A, Guyre PM, Holbrook NJ. Physiological functions of glucocorticoids in stress and their relation to pharmacological actions. Endocr Rev. 1984;5(1):25-44. 
105. Walev I, Klein J, Husmann M, et al. Potassium regulates IL-1 beta processing via calcium-independent phospholipase A2. J Immunol. 2000;164(10):5120-5124.

106. Wu C-C, Croxtall JD, Perretti M, et al. Lipocortin 1 mediates the inhibition by dexamethasone of the induction by endotoxin of nitric oxide synthase in the rat. Proc Natl Acad Sci U S A. 1995;92(8):3473-3477.

107. Lasa M, Abraham SM, Boucheron C, Saklatvala J, Clark AR. Dexamethasone causes sustained expression of mitogen-activated protein kinase (MAPK) phosphatase 1 and phosphatase-mediated inhibition of MAPK p38. Mol Cell Biol. 2002;22(22):7802-7811.

108. Crafford LJ, Wilder RL, Ristimaki AP, et al. Cyclooxygenase-1 and -2 expression in rheumatoid arthritis synovial tissues. J Clin Invest. 1994;93(3):1095-1101.

109. Radomski MW, Palmer RM, Moncada S. Glucocorticoids inhibit the expression of an inducible, but not the constitutive, nitric oxide synthase in vascular endothelial cells. Proc Natl Acad Sci U S A. 1990;87(24): 10043-10047.

110. Hoeck WG, Ramesha CS, Chang DJ, Fan N, Heller RA. Cytoplasmic phospholipase $\mathrm{A}_{2}$ activity and gene expression are stimulated by tumor necrosis factor: dexamethasone blocks the inducible synthesis. Proc Natl Acad Sci U S A. 1993;90(10):4475-4479.

111. Kunicka JE, Talle MA, Denhardt GH, Brown M, Prince LA, Goldstein G. Immunosuppression by glucocorticoids: inhibition of production of multiple lymphokines by in vivo administration of dexamethasone. Cell Immunol. 1993;149(1):39-49.

112. Calandra T, Bernhagen J, Metz CN, et al. MIF as a glucocorticoid-induced modulator of cytokine production. Nature. 1995;377(6544):68-71.

113. Salvemini D, Seibert K, Masferrer JL, Misko TP, Currie MG, Needleman P. Endogenous nitric oxide enhances prostaglandin production in a model of renal inflammation. $J$ Clin Invest. 1994;93(5):1940-1947.

114. Zaitsu M, Hamasaki Y, Tsuji K, et al. Dexamethasone accelerates catabolism of leukotriene $\mathrm{C}_{4}$ in bronchial epithelial cells. Eur Respir J. 2003;22(1):35-42.

115. Dworski R, Fitzgerald GA, Oates JA, Sheller JR. Effect of oral prednisone on airway inflammatory mediators in atopic asthma. Am J Respir Crit Care Med. 1994;149(4 Pt 1):953-959.

116. Ferrante JV, Ferrante A. Novel role of lipoxygenases in the inflammatory response: promotion of TNF mRNA decay by 15-hydroperoxyeicosatetraenoic acid in a monocytic cell line. J Immunol. 2005;174(6):3169-3172.

117. Ariel A, Chiang N, Arita M, Petasis NA, Serhan CN. Aspirin-triggered lipoxin A4 and B4 analogs block extracellular signal-regulated kinasedependent TNF-alpha secretion from human T cells. $J$ Immunol. 2003;170(12):6266-6272.

118. Wu SH, Lu C, Dong L, Zhou GP, He ZG, Chen ZQ. Lipoxin A4 inhibits TNF-alpha-induced production of interleukins and proliferation of rat mesangial cells. Kidney Int. 2005;68(1):35-46.

119. Hayakawa M, Ishida N, Takeuchi K, et al. Arachidonic acid-selective cytosolic phospholipase $\mathrm{A}_{2}$ is crucial in the cytotoxic action of tumor necrosis factor. J Biol Chem. 1993;268(15):11290-11295.

120. Das UN. A Perinatal Strategy for Preventing Adult Disease: The Role of Long-chain Polyunsaturated Fatty Acids. Boston: Kluwer Academic Press; 2002.

121. Huang YS, Drummond R, Horrobin DF. Protective effect of gammalinolenic acid on aspirin induced gastric hemorrhage in rats. Digestion. 1987;36(1):36-41.

122. Manjari V, Das UN. Effect of polyunsaturated fatty acids on dexamethasone-induced gastric mucosal damage. Prostaglandins Leukot Essent Fatty Acids. 2000;62(2):85-96.

123. Das UN. Essential fatty acids and their metabolites could function as endogenous HMG-CoA reductase and ACE enzyme inhibitors, antiarrhythmic, anti-hypertensive, anti-atherosclerotic, anti-inflammatory, cytoprotective, and cardioprotective molecules. Lipids Health Dis. 2008;7:37.
124. Das UN. Can essential fatty acids reduce the burden of disease(s)? Lipids Health Dis. 2008;7:9.

125. Das UN. Essential fatty acids - a review. Curr Pharm Biotechnol. 2006;7(6):467-482.

126. Krishna Mohan I, Das UN. Prevention of chemically induced diabetes mellitus in experimental animals by polyunsaturated fatty acids. Nutrition. 2001;17(2):126-151.

127. Suresh Y, Das UN. Long-chain polyunsaturated fatty acids and chemically-induced diabetes mellitus: effect of $\omega-6$ fatty acids. Nutrition. 2003;19(2):93-114.

128. Suresh Y, Das UN. Long-chain polyunsaturated fatty acids and chemically-induced diabetes mellitus: effect of $\omega-3$ fatty acids. Nutrition. 2003;19(3):213-228.

129. Suresh Y, Das UN. Differential effect of saturated, monounsaturated, and polyunsaturated fatty acids on alloxan-induced diabetes mellitus. Prostaglandins Leukot Essent Fatty Acids. 2006;74(3): 199-213.

130. Das UN, Mohan IK, Raju TR. Effect of corticosteroids and eicosapentaenoic acid/docosahexaenoic acid on pro-oxidant and antioxidant status and metabolism of essential fatty acids in patients with glomerular disorders. Prostaglandins Leukot Essent Fatty Acids. 2001;65(4):197-203.

131. Das UN. Essential fatty acids: biochemistry, physiology, and pathology. Biotechnol J. 2006;1(4):420-439.

132. Kambe T, Murakami M, Kudo I. Polyunsaturated fatty acids potentiate interleukin-1-stimulated arachidonic acid release by cells overexpressing type IIA secretory phospholipase A2. FEBS Lett. 1999;453(1-2):81-84.

133. Das UN. Can perinatal supplementation of long-chain polyunsaturated fatty acids prevent atopy, bronchial asthma and other inflammatory conditions? Med Sci Monit. 2006;12(6):RA99-RA111.

134. Belmont HM, Levartovsky D, Goel A, et al. Increased nitric oxide production accompanied by the up-regulation of inducible nitric oxide synthase in vascular endothelium from patients with systemic lupus erythematosus. Arthritis Rheum. 1997;40(10):1810-1816.

135. Wanchu A, Khullar M, Deodhar SD, Bambery P, Sud A. Nitric oxide synthesis is increased in patients with systemic lupus erythematosus. Rheumatol Int. 1998;18(2):41-43.

136. Oates JC, Christensen EF, Reilly CM, Self SE, Gilkeson GS. Prospective measure of serum 3-nitrotyrosine levels in systemic lupus erythematosus: correlation with disease activity. Proc Assoc Am Physicians. 1999;111(6):611-621.

137. Svenungsson E, Andersson M, Brundin L, et al. Increased levels of proinflammatory cytokines and nitric oxide metabolites in neuropsychiatric lupus erythematosus. Ann Rheum Dis. 2001;60(4): 372-379.

138. Gilkeson G, Cannon C, Oates J, Reilly C, Goldman D, Petri M. Correlation of serum measures of nitric oxide production with lupus disease activity. $J$ Rheumatol. 1999;26(2):318-324.

139. Yu CC, Yang CW, Wu MS, et al. Mycophenolate mofetil reduces renal cortical inducible nitric oxide synthase mRNA expression and diminishes glomerulosclerosis in MRL/lpr mice. J Lab Clin Med. 2001;138(1):69-77.

140. Reilly CM, Oates JC, Sudian J, Crosby MB, Halushka PV, Gilkeson GS. Prostaglandin J(2) inhibition of mesangial cell iNOS expression. Clin Immunol. 2001;98(3):337-345.

141. Lemire JM, Adams JS, Kermani-Arab V, Bakke AC, Sakai R, Jordan SC. 1,25-Dihydroxyvitamin D3 suppresses human T helper/ inducer lymphocyte activity in vitro. J Immunol. 1985;134(5): 3032-3035.

142. Pichler J, Gerstmayr M, Szépfalusi Z, Urbanek R, Peterlik M, Willheim M. 1 alpha,25(OH)2D3 inhibits not only Th1 but also Th2 differentiation in human cord blood T cells. Pediatr Res. 2002;52(1): $12-18$.

143. Tang J, Zhou R, Luger D, et al. Calcitriol suppresses antiretinal autoimmunity through inhibitory effects on the Th17 effector response. J Immunol. 2009;182(8):4624-4632. 
144. Huang LW, Chang KL, Chen CJ, Liu HW. Arginase levels are increased in patients with rheumatoid arthritis. Kaohsiung J Med Sci. 2001;17(7):358-363.

145. Bultink IE, Teerlink T, Heijst JA, Dijkmans BA, Voskuyl AE. Raised plasma levels of asymmetric dimethylarginine are associated with cardiovascular events, disease activity, and organ damage in patients with systemic lupus erythematosus. Ann Rheum Dis. 2005;64(9):1362-1365.

146. Svenungsson E, Cederholm A, Jensen-Urstad K, Fei GZ, de Faire U, Frostegård J. Endothelial function and markers of endothelial activation in relation to cardiovascular disease in systemic lupus erythematosus. Scand J Rheumatol. 2008;37(5):352-359.

147. Gustafsson J, Gunnarsson I, Börjesson O, et al. Predictors of the first cardiovascular event in patients with systemic lupus erythematosus - a prospective cohort study. Arthritis Res Ther. 2009; 11(6):R186.

148. Das UN. Beneficial effect of L-arginine in collagen vascular diseases: a role for nitric oxide. Nutrition. 1993;9(3):277-278

149. Fries R, Shariat K, von Wilmowsky H, Böhm M. Sildenafil in the treatment of Raynaud's phenomenon resistant to vasodilatory therapy. Circulation. 2005;112(19):2980-2985.

150. Yoshizumi M, Kunihara $\mathrm{H}$, Morita $\mathrm{T}$, et al. Interleukin-1 increases the production of endothelin-1 by cultured endothelial cells. Biochem Biophys Res Commun. 1990;166(1):324-329.

151. Liu J, Farmer JD Jr, Lane WS, Friedman J, Weissman I, Schreiber S. Calcineurin is a common target of cyclophilin-cyclosporin A and FKBP-FK506 complexes. Cell. 1991;66(4):807-815.

152. Dong G, Panaro F, Bogetti D, et al. Standard chronic immunosuppression after kidney transplantation for systemic lupus erythematosus eliminates recurrence of disease. Clin Transplant. 2005;19(1):56-60.

153. Tanaka H, Oki E, Tsuruga K, Yashiro T, Hanada I, Ito E. Management of young patients with lupus nephritis using tacrolimus administered as a single daily dose. Clin Nephrol. 2009;72(6):430-436.

154. Yoon KH. Efficacy and cytokine modulating effects of tacrolimus in systemic lupus erythematosus: a review. J Biomed Biotechnol. 2010;2010:686480

155. Pego-Reigosa JM, Isenberg DA. Systemic lupus erythematosus: pharmacological developments and recommendations for a therapeutic strategy. Expert Opin Investig Drugs. 2008;17(1):31-41.

156. Edwards JC, Szczepanski L, Szechinski J, et al. Efficacy of B-celltargeted therapy with rituximab in patients with rheumatoid arthritis. N Engl J Med. 2004;350(25):2572-2581.

157. Sabahi R, Anolik JH. B-cell-targeted therapy for systemic lupus erythematosus. Drugs. 2006;66(15):1933-1948.

158. Ding C, Foote S, Jones G. B-cell-targeted therapy for systemic lupus erythematosus: an update. BioDrugs. 2008;22(4):239-249.

159. Hicks PS, Saunero-Nava L, Du Clos TW, Mold C. Serum amyloid P component binds to histones and activates the classical complement pathway. J Immunol. 1992;149(11):3689-3694.

160. Bickerstaff MC, Botto M, Hutchinson WL, et al. Serum amyloid P component controls chromatin degradation and prevents antinuclear autoimmunity. Nat Med. 1999;5(6):694-697.

161. Gillmore JD, Hutchinson WL, Herbert J, et al. Autoimmunity and glomerulonephritis in mice with targeted deletion of the serum amyloid P component gene: SAP deficiency or strain combination? Immunology. 2004;112:255-264.

162. Braun A, Sis J, Max R, et al. Anti-chromatin and anti-C1q antibodies in systemic lupus erythematosus compared to other systemic autoimmune diseases. Scand J Rheumatol. 2007;36(4):291-298.

163. Soma M, Tamaoki T, Kawano H, et al. Mice lacking serum amyloid $\mathrm{P}$ component do not necessarily develop severe autoimmune disease. Biochem Biophys Res Commun. 2001;286(1):200-205.

164. Tsukamoto H, Horiuchi T. Clinical aspects of the complement system. Rinsho Byori. 2006;54(7):757-762.

165. Chen M, Daha MR, Kallenberg CG. The complement system in systemic autoimmune disease. J Autoimmun. 2010;34(3):J276-J286.
166. Braude IA, Hochberg MC, Arnett FC, Waldmann TA. In vitro suppression of anti-DNA antibody and immunoglobulin synthesis in systemic lupus erythematosus patients by human gamma interferon. J Rheumatol. 1988;15(3):438-444.

167. Nicoletti F, Meroni P, di Marco R, et al. In vivo treatment with a monoclonal antibody to interferon-gamma neither affects the survival nor the incidence of lupus-nephritis in the MRL/lpr-lpr mouse. Immunopharmacology. 1992;24(1):11-16.

168. Rönnblom L, Pascual V. The innate immune system in SLE: type I interferons and dendritic cells. Lupus. 2008;17(5):394-399.

169. Satomi N, Sakurai A, Haranaka K. Relationship of hypoglycemia to tumor necrosis factor production and antitumor activity: role of glucose, insulin, and macrophages. $J$ Natl Cancer Inst. 1985;74(6):1255-1260.

170. Fraker DL, Merino MJ, Norton JA. Reversal of the toxic effects of cachectin by concurrent insulin administration. Am J Physiol. 1989;256(6 Pt 1):E725-E731.

171. Ottlecz A, Koltai M, Blazso G, Minker E. Contribution to the regulatory role of insulin in inflammation and anaphylaxis. Int Arch Allergy Appl Immunol. 1978;56(3):284-286.

172. Ottlecz A, Koltai M, Gecse A. Further studies on the antiinflammatory effect of insulin. Agents Actions. 1977;7:487-491.

173. Ottlecz A, Gecse A, Koltai M, West GB. Involvement of the kinin system in the insulin-induced inhibition of carrageenin oedema in rats. Monogr Allergy. 1977;12:131-137.

174. Boichot E, Sannomiya P, Escofier N, et al. Endotoxin-induced acute lung injury in rats. Role of insulin. Pulm Pharmacol Ther. 1999;12(5):285-290.

175. Das UN. Is insulin an antiinflammatory molecule? Nutrition. 2001;17(5):409-413.

176. Kuboki K, Jiang ZY, Takahara N, et al. Regulation of endothelial constitutive nitric oxide synthase gene expression in endothelial cells and in vivo: a specific vascular action of insulin. Circulation. 2000;101(6):676-681.

177. Kojda G, Harrison D. Interaction between NO and reactive oxygen species: pathophysiological importance in atherosclerosis, hypertension, diabetes and heart failure. Cardiovasc Res. 1999;43(3): 562-571.

178. Sakaue S, Nishihira J, Hirokawa J, et al. Regulation of macrophage migration inhibitory factor (MIF) expression by glucose and insulin in adipocytes in vitro. Mol Med. 1999;5(6):361-371.

179. Waeber G, Calandra T, Roduit R, et al. Insulin secretion is regulated by the glucose-dependent production of islet beta cell macrophage migration inhibitory factor. Proc Natl Acad Sci U S A. 1997;94(9):4782-4787.

180. Hirokawa J, Sakaue S, Furuya Y, et al. Tumor necrosis factor alpha regulates the gene expression of macrophage migration inhibitory factor through tyrosine kinase-dependent pathway in 3T3-L1 adipocytes. J Biochem (Tokyo). 1998;123(4):733-739.

181. Hotamisligil GS. The role of TNFalpha and TNF receptors in obesity and insulin resistance. J Intern Med. 1999;245(6):621-625.

182. Das UN. Possible beneficial action(s) of glucose-insulin-potassium regimen in acute myocardial infarction and inflammatory conditions: a hypothesis. Diabetologia. 2000;43(8):1081-1082.

183. Das UN. Can glucose-insulin-potassium regimen suppress inflammatory bowel disease? Med Hypotheses. 2001;57(2):183-185.

184. Das UN. Hypothesis: can glucose-insulin-potassium regimen in combination with polyunsaturated fatty acids suppress lupus and other inflammatory diseases? Prostaglandins Leukot Essent Fatty Acids. 2001;65(2):109-113.

185. Li J, Zhang $\mathrm{H}, \mathrm{Wu} \mathrm{F}$, et al. Insulin inhibits tumor necrosis factor$\alpha$-induction in myocardial ischemia/reperfusion: role of Akt and endothelial nitric oxide synthase phosphorylation. Crit Care Med. 2008;36(5):1551-1558.

186. Reade MC, Fink MP. Bench-to-bedside review: amelioration of acute renal impairment using ethyl pyruvate. Crit Care. 2005;9(6):556-560. 
187. Sims CA, Wattanasirichaigoon S, Menconi MJ, Ajami AM, Fink MP. Ringer's ethyl pyruvate solution ameliorates ischemia/ reperfusion-induced intestinal mucosal injury in rats. Crit Care Med. 2001;29(8):1513-1518.

188. Tawadrous ZS, Delude RL, Fink MP. Resuscitation from hemorrhagic shock with Ringer's ethyl pyruvate solution improves survival and ameliorates intestinal mucosal hyperpermeability in rats. Shock. 2002;17(6):473-477.

189. Dobsak P, Courderot-Masuyer C, Zeller M, et al. Antioxidative properties of pyruvate and protection of the ischemic rat heart during cardioplegia. J Cardiovasc Pharmacol. 1999;34(5):651-659.

190. Cicalese L, Lee K, Schraut W, Watkins S, Borle A, Stanko R. Pyruvate prevents ischemia-reperfusion mucosal injury of rat small intestine. Am J Surg. 1996;171(1):97-100.

191. Venkataraman R, Kellum JA, Song M, Fink MP. Resuscitation with Ringer's ethyl pyruvate solution prolongs survival and modulates plasma cytokine and nitrite/nitrate concentrations in a rat model of lipopolysaccharide-induced shock. Shock. 2002;18(6):507-512.

192. Das UN. Pyruvate is an endogenous anti-inflammatory and anti-oxidant molecule. Med Sci Monit. 2006;12(5):RA79-RA84.

193. Das UN. Is pyruvate an endogenous anti-inflammatory molecule? Nutrition. 2006;22(9):965-972.

194. Das UN. Ethyl pyruvate in sepsis. Adv Sepsis. 2007;6:10-15.

195. Belayev L, Marcheselli VL, Khoutorova L, et al. Docosahexaenoic acid complexed to albumin elicits high-grade ischemic neuroprotection. Stroke. 2005;36(1):118-123.

196. Das UN. Albumin infusion therapy in stroke, sepsis and the critically ill. Curr Nutr Food Sci. 2008;4:217-226.

197. Borovikova LV, Ivanova S, Zhang M, et al. Vagus nerve stimulation attenuates the systemic inflammatory response to endotoxin. Nature. 2000;405(6785):458-462.

198. Wang H, Yu M, Ochani M, et al. Nicotinic acetylcholine receptor alpha7 subunit is an essential regulator of inflammation. Nature. 2003;421(6921):384-388.

199. Karimi K, Bienenstock J, Wang L, Forsythe P. The vagus nerve modulates CD4+ T cell activity. Brain Behav Immun. 2010;24(2):316-323.
200. Westman M, Engström M, Catrina AI, Lampa J. Cell specific synovial expression of nicotinic alpha 7 acetylcholine receptor in rheumatoid arthritis and psoriatic arthritis. Scand J Immunol. 2009;70(2):136-140.

201. Bruchfeld A, Goldstein RS, Chavan S, et al. Whole blood cytokine attenuation by cholinergic agonists ex vivo and relationship to vagus nerve activity in rheumatoid arthritis. $J$ Intern Med. 2010;268(1):94-101.

202. van Maanen MA, Stoof SP, Larosa GJ, Vervoordeldonk MJ, Tak PP. Role of the cholinergic nervous system in rheumatoid arthritis: aggravation of arthritis in nicotinic acetylcholine receptor alpha7 subunit gene knockout mice. Ann Rheum Dis. 2010;69(9): 1717-1723.

203. Jobst BC. Electrical stimulation in epilepsy: vagus nerve and brain stimulation. Curr Treat Options Neurol. 2010;12(5): 443-453.

204. Li WG, Gavrila D, Liu X, et al. Ghrelin inhibits proinflammatory responses and nuclear factor-kappaB activation in human endothelial cells. Circulation. 2004;109(18):2221-2226.

205. Wu R, Dong W, Cui X, et al. Ghrelin down-regulates proinflammatory cytokines in sepsis through activation of the vagus nerve. Ann Surg. 2007;245(3):480-486.

206. Wu R, Zhou M, Das P, et al. Ghrelin inhibits sympathetic nervous activity in sepsis. Am J Physiol Endocrinol Metab. 2007; 293(6):E1697-E1702.

207. Chorny A, Anderson P, Gonzalez-Rey E, Delgado M. Ghrelin protects against experimental sepsis by inhibiting high-mobility group box 1 release and by killing bacteria. J Immunol. 2008;180(12): 8369-8377.

208. Wu R, Dong W, Zhou M, et al. Ghrelin attenuates sepsis-induced acute lung injury and mortality in rats. Am J Respir Crit Care Med. 2007;176(8):805-813.

209. Chang L, Zhao J, Yang J, Zhang Z, Du J, Tang C. Therapeutic effects of ghrelin on endotoxic shock in rats. Eur J Pharmacol. 2003;473(2-3):171-176.
Journal of Inflammation Research

\section{Publish your work in this journal}

The Journal of Inflammation Research is an international, peer-reviewed open-access journal that welcomes laboratory and clinical findings on the molecular basis, cell biology and pharmacology of inflammation including original research, reviews, symposium reports, hypothesis formation and commentaries on: acute/chronic inflammation; mediators of inflamma-

\section{Dovepress}

tion; cellular processes; molecular mechanisms; pharmacology and novel anti-inflammatory drugs; clinical conditions involving inflammation. The manuscript management system is completely online and includes a very quick and fair peer-review system. Visit http://www.dovepress.com/ testimonials.php to read real quotes from published authors. 